\title{
28 Research Suare \\ CGRP Signals from Endosomes of Schwann Cells to Elicit Migraine Pain
}

Francesco De Logu

University of Florence

Romina Nassini

University of Florence

Alan Hegron

College of Dentistry, New York University, New York

Lorenzo Landini

University of Florence https://orcid.org/0000-0002-3933-2497

Dane Jensen

NYU College of Dentistry https://orcid.org/0000-0001-6540-2375

Rocco Latorre

New York University, New York

Julia Ding

Columbia University, New York

Matilde Marini

University of Florence

Daniel Souza Monteiro de Araujo

https://orcid.org/0000-0003-1115-725X

Paulina Ramírez-Garcia

Monash Institute of Pharmaceutical Sciences

Michael Whittaker

Monash University

Jeffri Retamal

Monash Institute of Pharmaceutical Sciences

Mustafa Titiz

University of Florence

Alessandro Innocenti

Careggi University Hospital

Nicholas Veldhuis

Monash Institute of Pharmaceutical Sciences https://orcid.org/0000-0002-8902-9365

Thomas Davis

University of Queensland

Brian Schmidt 
New York University https://orcid.org/0000-0002-2409-8984

\section{Nigel Bunnett}

Columbia University https://orcid.org/0000-0003-3367-0644

\section{Pierangelo Geppetti ( $\nabla$ geppetti@unifi.it )}

University of Florence https://orcid.org/0000-0003-3797-8371

\section{Article}

Keywords: CGRP, CLR, RAMP1, Schwann cell, endosome, ROS, TRPA1, migraine, pain, allodynia

Posted Date: August 24th, 2021

DOI: https://doi.org/10.21203/rs.3.rs-758153/v1

License: (c) (i) This work is licensed under a Creative Commons Attribution 4.0 International License. Read Full License

Version of Record: A version of this preprint was published at Nature Communications on February 3rd, 2022. See the published version at https://doi.org/10.1038/s41467-022-28204-z. 


\section{Abstract}

Efficacy of monoclonal antibodies against calcitonin gene-related peptide (CGRP) or its receptor (calcitonin receptor-like receptor/receptor activity modifying protein-1, CLR/RAMP1) implicates peripherally-released CGRP in migraine pain. However, the site and mechanism of CGRP-evoked migraine pain remain unknown. By cell-selective RAMP1 gene deletion, we reveal that CGRP released from mouse cutaneous trigeminal fibers targets CLR/RAMP1 on surrounding Schwann cells to evoke periorbital mechanical allodynia. CLR/RAMP1 activation in human and mouse Schwann cells generates long-lasting signals from endosomes that evoke cAMP-dependent formation of NO. NO, by gating Schwann cell transient receptor potential ankyrin 1 (TRPA1), releases ROS, which in a feed-forward manner sustain allodynia via nociceptor TRPA1. When encapsulated into nanoparticles that release cargo in acidified endosomes, a CLR/RAMP1 antagonist provides superior inhibition of CGRP signaling and allodynia in mice. The CGRP-mediated neuronal/Schwann cell pathway is critical to mediate allodynia associated with neurogenic inflammation, thus contributing to the pro-migraine action of CGRP.

\section{Introduction}

For almost a century it has been known that cutaneous tissue injury elicits a local vascular response, referred to as neurogenic inflammation, that is associated to a wider area of increased sensitivity to mechanical stimuli ${ }^{1}$. A subset of C-fiber primary afferents, which mediate neurogenic inflammation, is the main source of the neuropeptides substance $P(S P)$ and calcitonin gene related peptide (CGRP) 2,3 . In rodents, noxious stimuli such as capsaicin, a pungent agonist of the transient receptor potential vanilloid 1 (TRPV1) channel ${ }^{4}$, evoke peripheral release of CGRP which induces arteriolar vasodilatation ${ }^{2}$ and of SP which elicits plasma protein extravasation ${ }^{5}$, and produce sensory responses, which encompasses acute nociception and prolonged mechanical allodynia ${ }^{6}$. Capsaicin administration to the human skin elicits a similar pattern of responses, consisting of local cutaneous vasodilatation, but not plasma extravasation ${ }^{7}$, and focal and transient burning pain ( $\mathrm{min}$ ) associated with widespread, sustained mechanical hypersensitivity $(\mathrm{hrs})^{8}$. While CGRP has been identified as the mediator of neurogenic vasodilatation in rodents ${ }^{2}$ and humans ${ }^{9}$, the cellular and molecular mechanisms underlying mechanical allodynia associated with neurogenic inflammation are unknown.

The efficacy of small molecule antagonists of CGRP receptor ${ }^{10}$ and of monoclonal antibodies to CGRP or its receptor ${ }^{11}$ highlights the prominent role of CGRP in migraine pain. The poor penetration of the blood brain barrier by some antagonists ${ }^{12,13}$, and monoclonal antibodies ${ }^{14}$ underlines the peripheral origin of CGRP-mediated migraine pain. However, little information exists on the proalgesic action of CGRP in the periphery. In mice, intraplantar injection of CGRP evokes mechanical allodynia ${ }^{15}$ and systemic CGRP causes facial grimace ${ }^{16}$. CGRP injection into the periorbital area, while failing to evoke spontaneous nociceptive behavior, produces sustained $(\sim 4 \mathrm{~h})$ periorbital mechanical allodynia (PMA) ${ }^{17}$. CGRP released from trigeminal peripheral terminals contributes to PMA in mice ${ }^{18}$ evoked by systemic 
(intraperitoneal) administration of the pro-migraine agent glyceryl trinitrate (GTN) ${ }^{19}$. Facial cutaneous allodynia is a hallmark of migraine pain ${ }^{20,21}$. However, the anatomical site in the peripheral nervous system and the signaling pathways of CGRP-evoked mechanical hypersensitivity, possibly implicated in migraine pain, are unknown.

The CGRP receptor is a heterodimer of calcitonin receptor-like receptor (CLR), a G protein-coupled receptor (GPCR), and receptor activity-modifying protein 1 (RAMP1), a single transmembrane domain CLR chaperone ${ }^{22}$. These two components coexist in cells that mediate the actions of CGRP, for example vascular myocytes ${ }^{2}$. Satellite glial cells and Schwann cells express CLR/RAMP1 and are closely associated with peptidergic sensory neurons ${ }^{23}$. While the extracellular space between the soma of trigeminal neurons and satellite glial cells is not a recognized locus for neurotransmission, the varicosities of $\mathrm{C}$-fibers and the ensheathing Schwann cells are sites where neuropeptides, including $\mathrm{CGRP}^{24}$, are normally released. Schwann cells from rat sciatic nerve respond to CGRP by increasing intracellular cAMP level ${ }^{25}$ and CLR/RAMP1 are expressed by Schwann cells that wrap CGRP + ve terminals of rat nociceptors ${ }^{23,26,27}$. Schwann cells mediate mechanical allodynia in mouse models of neuropathic and cancer pain ${ }^{28,29}$. Cutaneous Schwann cells can also directly activate sensory nerves to promote mechanical nociception ${ }^{30}$. Although GPCRs are usually considered to signal principally from the plasma membrane, GPCR kinases and $\beta$-arrestins ( $\beta$ ARRs) rapidly terminate this signaling. Persistent endosomal signaling of GPCRs, including CLR/RAMP1, underlies sustained neuronal activation and nociception in the central nervous system (CNS) $31,32,33$.

Herein, we hypothesized that mechanical allodynia associated with neurogenic inflammation is mediated by CGRP which targets CLR/RAMP1 in Schwann cells ensheathing peripheral endings of nociceptors. By selective RAMP1 gene deletion in Schwann cells, we reveal that CGRP released from trigeminal terminals causes PMA by paracrine signaling to the surrounding Schwann cells. We also hypothesized that persistent CGRP/CLR/RAMP1 signaling from endosomes in Schwann cells underlies sustained PMA. By using inhibitors of clathrin- and dynamin-mediated endocytosis and stimulus-responsive nanoparticles designed to release CLR/RAMP1 antagonists in acidified endosomes, we found that CLR/RAMP1 endosomal signaling results in a cAMP-dependent release of nitric oxide (NO), which activates transient receptor potential ankyrin 1 (TRPA1), a proalgesic channel and sensor of oxidative stress ${ }^{34}$. TRPA1, via NADPH oxidase 1 (NOX1), elicits an oxidative stress-dependent feed-forward mechanism that sustains allodynia. In two recognized mouse models of migraine, induced by systemic CGRP ${ }^{16}$ and GTN ${ }^{18}$ administration, selective deletion of Schwann cell RAMP1 attenuated PMA.

\section{Results}

\section{CGRP evokes PMA by activating Schwann cell CLR/RAMP1}

We detected CLR and RAMP1 mRNA and immunoreactivity in primary cultures of human and mouse Schwann cells (HSCs, MSCs) (Fig. 1a, Supplementary Fig. 1a). The S100 + ve mouse Schwann cell line 
(IMS32) recapitulated features of primary MSCs, including expression of CLR and RAMP1 mRNA and immunoreactivity (Supplementary Fig. 1a,b) and responsiveness to allyl isothiocyanate, which evoked a TRPA1-dependent increase in $\mathrm{Ca}^{2+}$ response (Supplementary Fig. 1c). Immunoreactive CLR and RAMP1 were also detected in S100 + ve Schwann cells in nerve bundles in biopsies of human abdominal and mouse periorbital skin (Fig. 1b).

To assess the role of Schwann cell CLR/RAMP1 in CGRP-evoked PMA, Schwann cell-specific Cre mice

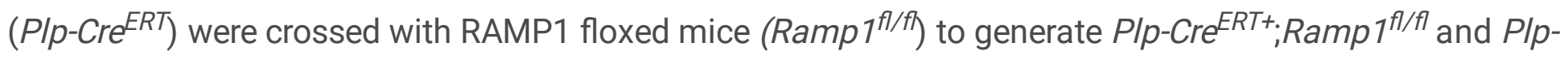
$C r e^{E R T-} ; R a m p 1^{f l / f l}$ (Control) mice. Unless otherwise specified, all drugs were administered by subcutaneous periorbital injection (Supplementary Table 1). For selective deletion of RAMP1 in Schwann cells of the periorbital region, 4-hydroxytamoxifen (4-OHT) was administered daily for 3 days to Plp$C r e^{E R T+} ; R^{2}$ amp $1^{f l / f l}$ and Control mice. In Control mice CGRP elicited allodynia in the periorbital area (Fig. 1c), but not at a distant site, such as the hind paw (Supplementary Fig. 1d). CGRP-evoked PMA was markedly attenuated in Plp-Cre ${ }^{E R T+} ; R a m p 1^{f l / f l}$ mice treated with 4-OHT (Fig. 1c). 4-OHT treatment downregulated RAMP1 immunoreactivity in S100 + ve cells surrounding trigeminal but not sciatic nerve fibers (Fig. 1d) and did not prevent paw mechanical allodynia evoked by intraplantar CGRP (Supplementary Fig. 1e). Intravenous CGRP provokes delayed migraine-like attacks in patients ${ }^{35}$. To mimic the human provocation test, intraperitoneal CGRP was given to Control mice which elicited PMA and paw allodynia (Fig. 1e,f). PMA, but not paw allodynia, was reduced in Plp-Cre ${ }^{E R T+}$;Ramp $1^{f l / f l}$ mice treated with 4-OHT (Fig. 1e,f). Systemic (intraperitoneal) 4-OHT reduced both PMA and paw allodynia (Supplementary Fig. 1f,g). These results reveal an essential role for CLR/RAMP1 of Schwann cells surrounding periorbital trigeminal endings in sustained PMA elicited by both local and systemic CGRP.

\section{Stimulation of peptidergic trigeminal neurons evokes PMA by activating Schwann cell CLR/RAMP1}

To explore the ability of endogenous CGRP to elicit PMA, we administered capsaicin, which activates TRPV $1^{4}$ and in rodents stimulates release of both CGRP and SP from terminals of peptidergic nociceptors ${ }^{3}$. Periorbital capsaicin dose-dependently elicited acute ( $10 \mathrm{~min}$ ) nociceptive behavior (Fig. 2a) and, like CGRP, caused prolonged ( 4 h) PMA (Fig. 2b). The proalgesic action was detected in the periorbital area but not in the hind paw (Supplementary Fig. 2a), indicating a local action. TRPV1 deletion (Trpv1 ${ }^{-/-}$mice) (Fig. 2c,d) or pretreatment with the TRPV1 antagonist capsazepine (Fig. 2e,f), prevented acute nociception and PMA. An antagonist $(\mathrm{L}-733,060)$ of the SP neurokinin 1 (NK 1 ) receptor, which prevented SP-evoked PMA (Fig. 2g), failed to diminish capsaicin-evoked acute nociception and PMA (Fig. 2h, Supplementary Fig. 2b). Local pretreatment with the histamine $\mathrm{H}_{1}$ receptor antagonist, astemizole, inhibited SP-evoked PMA (Supplementary Fig. 2c) but did not affect CGRP- or capsaicinevoked PMA (Supplementary Fig. 2d,e). Pretreatment with the CLR/RAMP1 antagonists, CGRP8-37 or olcegepant, prevented PMA (Fig. 2i,j) but not acute nociception evoked by capsaicin (Supplementary Fig. 2b). Importantly, 4-OHT markedly inhibited capsaicin-evoked PMA (Fig. 2k) but not acute nociception (Supplementary Fig. 2f) in Plp-Cre ${ }^{E R T+} ; R a m p 1^{f l / f l}$ mice as compared to Control mice. PMA elicited by CGRP or acute nociception and PMA elicited by capsaicin were similar in mice with selective deletion of 
RAMP1 in nociceptors ( $A d v-C r e^{+} ; R^{2} m p 1^{f / f f}$ ) and Control mice (Fig. 2l,m). In addition, both PMA and paw allodynia were similar in $A d v-C r e^{+} ; \operatorname{Ramp}^{f / / f l}$ and Control mice after intraperitoneal CGRP (Fig. 2n,o). Results imply two conclusions. First, CGRP but not SP mediates allodynia resulting from excitation of TRPV1 + ve peptidergic nociceptors. Second, PMA evoked by both endogenous and exogenous CGRP is dependent on CLR/RAMP1 of Schwann cells surrounding peripheral terminals of nociceptors, while the receptor of sensory nerve fibers is not implicated.

\section{Schwann cell CLR/RAMP1 mediates the CGRP-dependent PMA evoked by GTN}

Systemic GTN administration provokes migraine-like pain in humans ${ }^{19}$. In mice intraperitoneal GTN elicits $\mathrm{PMA}^{18}$, that is in part mediated by CGRP release from periorbital trigeminal terminals ${ }^{18}$. Here, we show that systemic (intraperitoneal) GTN elicited PMA (Fig. 3a) and paw allodynia (Fig. 3b) that were similar in Control and $\mathrm{Adv}-\mathrm{Cre}^{+} ; \mathrm{Ramp}^{f / / f l}$ mice. Olcegepant transiently and partially inhibited PMA (Fig. 3a), while did not affect paw allodynia (Fig. 3b) evoked by intraperitoneal GTN in both mouse strains. Deletion of RAMP1 by $4-\mathrm{OHT}$ in $\mathrm{Plp}-\mathrm{Cr} e^{E R T+} ; \mathrm{Ramp}^{f l / f l}$ mice partially inhibited PMA (Fig. 3c), but not paw allodynia (Fig. 3d). Importantly, treatment with olcegepant reduced GTN-evoked PMA in Control mice, but failed to further inhibit the response in Plp-Cre ${ }^{E R T+} ; R a m p 1^{f l / f l}$ mice (Fig. 3c). Paw allodynia was unchanged by olcegepant (Fig. 3d). Together, the findings suggest that Schwann cell CLR/RAMP1 mediates the CGRP-dependent component of PMA in an established mouse model of migraine pain.

\section{Clathrin- and dynamin-mediated endocytosis of CLR/RAMP1 in Schwann cells mediates PMA}

We investigated the CLR/RAMP1 signaling pathway in Schwann cells that mediates CGRP-evoked PMA. CGRP-stimulated cAMP formation was measured in HSCs using a virally-encoded CAMP cADDis reporter. CGRP stimulated a prompt concentration-dependent increase in cAMP formation in HSCs that was sustained for $>300 \mathrm{~s}$ (Fig. 4a,b; Video S1). The CLR/RAMP1 antagonist olcegepant caused a concentration-dependent inhibition of CGRP-stimulated cAMP formation (Fig. 4c-e).

Endosomal signaling of GPCRs, including CLR/RAMP1, controls nociception $31,32,33$. To assess CLR/RAMP1 endocytosis in Schwann cells, we incubated HSCs expressing the early endosome marker Rab5a-GFP with TAMRA-CGRP. In vehicle-treated cells, live cell imaging revealed uptake of TAMRA-CGRP into Rab5a-GFP + ve early endosomes within 10 min that continued for 30 min (Fig. 4f, Video S2). Inhibitors of clathrin (PitStop2, PS2) or dynamin (Dyngo4a, Dy4) prevented the translocation of TAMRACGRP to endosomes causing retention of weak TAMRA-CGRP fluorescence at the cell surface (Fig. 4e,f; Video S3,S4). Quantification of TAMRA-CGRP fluorescence intensity in Rab5a-GFP + ve endosomes or the proportion of endosomes containing TAMRA-CGRP confirmed that PS2 and Dy4 inhibited endocytosis of TAMRA-CGRP (Fig. 4g,h). Inactive analogs had no effect. Hypertonic sucrose (0.45 M) inhibits clathrinmediated endocytosis, including agonist-stimulated endocytosis of GPCRs ${ }^{36}$. Hypertonic sucrose also inhibited the uptake of TAMRA-CGRP in HSCs (Fig. 4g,h, Video S5). Periorbital injection of PS2 or Dy4 prevented CGRP- and capsaicin-evoked PMA, whereas inactive analogs had no effect (Fig. 4i-I). Thus, 
CGRP stimulates clathrin- and dynamin-mediated endocytosis of CLR/RAMP1 in Schwann cells, which sustains CGRP-evoked PMA.

\section{CLR activates $\mathrm{Ga}_{\mathrm{s}}, \mathrm{Ga}_{\mathrm{q}}$ and $\mathrm{Ga}_{\mathrm{i}}$ and recruits $\beta A R R 2$ to the plasma membrane and endosomes}

GPCRs, including CLR/RAMP1, can signal from endosomes by $\mathrm{Ga}_{\mathrm{s}}, \mathrm{Ga}_{\mathrm{q}}$ and $\beta A R R$-mediated mechanisms ${ }^{31}, 32,33$. We used enhanced bystander bioluminescence resonance energy transfer (EbBRET) to study the activation of $\mathrm{Ga}$ and recruitment of $\beta A R R$ to the plasma membrane and early endosomes of HEK293T cells expressing human (h) CLR and RAMP1 (HEK-hCLR/RAMP1). CGRP-dependent activation of $\mathrm{Ga}_{\mathrm{s}}, \mathrm{Ga}_{\mathrm{sq}}$ and $\mathrm{Ga}_{\mathrm{si}}$ was assessed using an EbBRET assay that detects recruitment of mini $(\mathrm{m}) \mathrm{Ga}$ coupled to Renilla (R)luc8 to the plasma membrane marker CAAX coupled to RGFP or the early endosome marker Rab5a coupled to tandem (td)RGFP. mGa proteins are N-terminally truncated Ga proteins that freely diffuse throughout the cytoplasm and bind to active conformations of GPCRs. Their translocation to GPCRs reflects $\mathrm{Ga}$ activation. $\mathrm{mGa}_{\mathrm{sq}}$ and $\mathrm{mGa}_{\mathrm{si}}$ were developed by mutating $\mathrm{mGa}_{\mathrm{s}}$ residues to equivalent $\mathrm{Ga}_{\mathrm{q}}$ and $\mathrm{Ga}_{\mathrm{i}}$ residues. Recruitment of $\beta A R R$ was assessed by measuring EbBRET between Rluc2-BARR2 and RGFP-CAAX or tdRGFP-Rab5a. CGRP induced a rapid increase in EbBRET between Rluc8-mGa $a^{\prime}$ Rluc8-mGa $a_{s q}$ Rluc8-mGa ${ }_{s i}$ and Rluc2- $\beta A R R 2$ with RGFP-CAAX, which was maximal at $~ 300$ $s$ and declined over $1000 \mathrm{~s}$ (Fig. 5a,b). CGRP increased EbBRET between Rluc8-mGa $a_{s}$ Rluc8-mGa ${ }_{s q}$, Rluc8-mGa $\mathrm{si}_{\mathrm{si}}$ and Rluc2- $\beta$ ARR2 with tdRGFP-Rab5a that was fully sustained for $1300 \mathrm{~s}$ (Fig. $5 \mathrm{c}, \mathrm{d}$ ). EbBRET was similarly used to study the activation of $\mathrm{Ga}$ and recruitment of $\beta A R R 2$ to the plasma membrane and endosomes of HSCs transfected with hCLR/RAMP1 (CLR/RAMP1 overexpression was required to amplify BRET signals). In HSCs, CGRP increased EbBRET between Rluc8-mGa, ${ }_{s}$ Rluc8-mGa $a_{s q}$ Rluc8-mGa $\mathrm{si}_{\mathrm{si}}$ and Rluc2-BARR2 with RGFP-CAAX and tdRGFP-Rab5a (Fig. 5e-h). EbBRET signals were sustained for $1300 \mathrm{~s}$.

To investigate the contribution of endocytosis to the activation of Ga proteins and $\beta A R R$ s in endosomes, we preincubated cells with hypertonic sucrose. CGRP increased EbBRET between hCLR-Rluc8 and tdRGFP-Rab5a in HEK-hCLR/RAMP1 cells, consistent with CLR endocytosis (Fig. 5i). Hypertonic sucrose inhibited these changes, which indicates an inhibition of endocytosis (Fig. 5i). Hypertonic sucrose caused a delayed yet more sustained activation of Rluc8- $\mathrm{mGa}_{\mathrm{s}}$, Rluc8- $\mathrm{mGa}_{\mathrm{sq}}$, Rluc8- $\mathrm{mGa}_{\mathrm{si}}$ and Rluc2- $\beta$ ARR2 at the plasma membrane (Supplementary Fig. 3a-f), and an almost complete inhibition of activation of

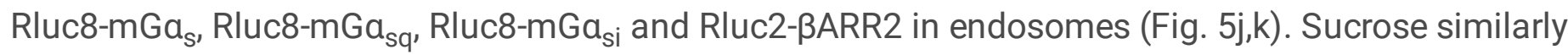
delayed CGRP-induced recruitment of Rluc8-mGa, Rluc8-mGa $a_{s q}$, Rluc8-mGa $a_{s i}$ and Rluc2-ßARR2 to the plasma membrane (Supplementary Fig. $3 \mathrm{~g}-\mathrm{I}$ ) and almost completely inhibited activation of $\mathrm{Ga}_{\mathrm{s}, \mathrm{sq}, \mathrm{si}}$ and $\beta A R R 2$ in endosomes of HSCs expressing hCLR/RAMP1 (Fig. 5I,m).

To examine the contribution of endosomal CLR/RAMP1 signaling to CGRP-induced cAMP formation, we preincubated HSCs expressing the CADDis CAMP reporter with sucrose or vehicle. In vehicle-treated cells, CGRP stimulated a rapid (1 min) increase in cAMP formation that was sustained for 30 min (Fig. 5n,o). Sucrose reduced but did not abolish the initial response, yet strongly inhibited the sustained phase of 
CGRP-stimulated cAMP formation (Fig. 5n,o). Thus, CGRP initially activates Ga and $\beta A R R$ at the plasma membrane, which is followed by sustained activation of Ga and $\beta A R R$ in early endosomes. Endocytosis is necessary for the recruitment of $\mathrm{Ga}$ and $\beta A R R$ to endosomes. $\mathrm{Ga}_{\mathrm{s}}$ continues to signal in endosomes, leading to sustained cAMP formation.

\section{CLR/RAMP1 activation in Schwann cells releases NO, which initiates but does not sustain PMA}

We investigated the mechanisms that sustain PMA following CLR/RAMP1 activation and endocytosis in Schwann cells. Pretreatment with CLR/RAMP1 antagonists, olcegepant or CGRP8-37, attenuated PMA evoked by capsaicin and in accordance with previous studies ${ }^{17,18}$ PMA evoked by CGRP (Supplementary Fig. 4a,b). In contrast, antagonists had no effect when administered 60 min after CGRP or capsaicin (Supplementary Fig. 4c-f). Similarly, inhibitors of clathrin- and dynamin-mediated endocytosis had no effect when administered 60 min after CGRP or capsaicin (Supplementary Fig. 4g-j). Thus, once induced by CGRP, CLR/RAMP1 antagonists or inhibitors of CRL/RAMP1 internalization are unable to attenuate PMA. Pre- but not post-treatment with the protein kinase A (PKA) inhibitor, H89, reduced PMA by CGRP and capsaicin (Supplementary Fig. 4k-n). NO has been implicated in CGRP-mediated vascular responses ${ }^{2}$. Although NO can release CGRP with proalgesic functions, the contribution of NO to CGRPevoked allodynia is uncertain. Pretreatment with an NO synthase (NOS) inhibitor (L-NAME) or an NO scavenger (CPTIO) (Fig. 6a), abrogated CGRP-evoked PMA (Fig. 6b,c). L-NAME and CPTIO pretreatment also attenuated capsaicin-evoked PMA (Fig. 6d,e). However, L-NAME and CPTIO did not affect PMA when administered 60 min after CGRP (Supplementary Fig. 4o,p) or capsaicin (Supplementary Fig. 4q,r). Thus, PKA-dependent NO release ${ }^{37}$ evoked by CGRP is necessary to initiate, but is not sufficient to sustain, allodynia.

In vitro findings recapitulated in vivo results. HSCs, MSCs and IMS32 cells predominantly expressed NOS3 (eNOS) mRNA, with little or no expression of NOS1 and NOS2 (nNOS and iNOS, respectively) mRNA (Fig. 6f,g; Supplementary Fig. 4s). In both HSCs and IMS32 cells, CGRP elicited a transient increase in NOS3 phosphorylation (i.e., activation), consistent with NO generation, which peaked at 5-10 min and declined within 30-60 min (Fig. 6h). In HSCs and IMS32 cells, the cAMP increase elicited by CGRP was prevented by olcegepant, CGRP8-37 and an adenylyl cyclase inhibitor (SQ22536), but not by L-NAME (Fig. 6i). The increase in CAMP evoked by CGRP but not that elicited by forskolin was reduced in cultured MSCs obtained from Plp-Cre ${ }^{E R T+} ; R_{\text {Ramp }}{ }^{f l f l}$ mice as compared to Control mice treated with intraperitoneal 4-OHT (Fig. 6j). In contrast, the CGRP-evoked increase in NO was attenuated by all these interventions, including NOS inhibition (Fig. 6k). The CAMP increase evoked by forskolin was unaffected by CLR/RAMP1 antagonism and NOS inhibition, and olcegepant failed to inhibit NO release by the NO donor NONOate (Supplementary Fig. 4t,u), indicating selectivity. PS2 and Dy4, but not their inactive analogs, inhibited CGRP-mediated NO release but did not affect NONOate-stimulated NO release (Supplementary Fig. 4v), further supporting selectivity. These results suggest that clathrin- and dynamin-dependent endocytosis and endosomal CLR/RAMP1 signaling evoke NOS activation and NO generation in Schwann cells. 


\section{Schwann cell TRPA1 mediates CGRP-evoked PMA}

NO belongs to a series of reactive oxygen species (ROS) that target TRPA ${ }^{38}$. TRPA 1 is coexpressed

with TRPV1 and CGRP in a subpopulation of primary sensory neurons ${ }^{39}$. TRPA1 is expressed in Schwann cells of nerve bundles of human skin and mouse sciatic nerve, where it mediates mechanical allodynia in rodent models of pain ${ }^{28,40}$. Immunoreactive TRPA1 was coexpressed with RAMP1 in S100+ve Schwann cells in human abdominal and mouse periorbital cutaneous nerves bundles (Fig. 7a). Thus, CLR/RAMP1 might engage signaling pathways that activate TRPA1 in trigeminal Schwann cells to initiate allodynia (Fig. 7b). The hypothesis that CLR/RAMP1 activates TRPA1 to induce allodynia was supported by the observation that both CGRP- and capsaicin-evoked PMA were reduced in Trpa ${ }^{\%}$ - mice and in mice with

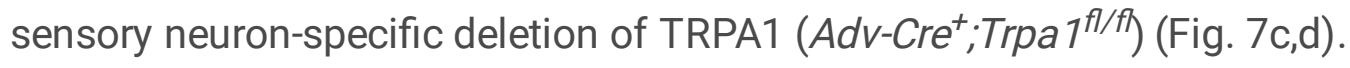

We next investigated the signaling pathway by which the CLR/RAMP1 activates TRPA1. In HSCs and IMS32 cells, CGRP stimulated a slowly developing yet sustained increase in $\mathrm{Ca}^{2+}$ response and increased $\mathrm{H}_{2} \mathrm{O}_{2}$ levels (Fig. 7e-g). Olcegepant, CGRP8-37, SQ22536, H89, L-NAME, $\mathrm{Ca}^{2+}$-free medium, ROS scavenger (PBN) or a NOX1 inhibitor (ML171) attenuated these responses (Fig. 7e-g). A TRPA1 antagonist (A967079) inhibited CGRP-stimulated $\mathrm{Ca}^{2+}$ and $\mathrm{H}_{2} \mathrm{O}_{2}$ responses (Fig. 7e-g) but did not affect CGRPstimulated NO formation (Fig. 7h). CGRP-evoked $\mathrm{Ca}^{2+}$ responses were reduced in Schwann cells from Trpa $1 \%$ mice (Supplementary Fig. 5a). These results support the hypothesis that CGRP liberates NO, which activates Schwann cell TRPA1; activated TRPA1 promotes a $\mathrm{Ca}^{2+}$-dependent $\mathrm{H}_{2} \mathrm{O}_{2}$ generation that sustains a feed-forward mechanism comprising TRPA1 channel engagement and ROS release.

In vivo results support the existence of a CGRP-evoked proalgesic pathway that is initiated by an NOdependent mechanism and sustained by ROS-mediated TRPA1 engagement. Whereas CLR/RAMP1 antagonists or NO inhibitors attenuated PMA only if given before CGRP or capsaicin, both pre- and posttreatment with a TRPA1 antagonist, a ROS scavenger and a NOX1 inhibitor reduced PMA (Fig. 7i-k; Supplementary Fig. 5b-d). Although pretreatment with TRPA1 or ROS inhibitors did not affect the acute nociception, they inhibited capsaicin-evoked PMA (Supplementary Fig. 5b-d). Post-treatment also attenuated capsaicin-evoked PMA (Supplementary Fig. 5b-d). These findings highlight the mechanistic differences between acute nociception and delayed PMA. After an initial and transient NO-dependent phase, PMA is sustained by persistent ROS liberation, which targets TRPA1 in Schwann cells. This hypothesis is robustly supported by the observation that PMA evoked by CGRP or capsaicin was markedly attenuated in mice with selective deletion of TRPA1 in Schwann cells $\left(P / p-C r e^{E R T+} ; \operatorname{Trpa} 1^{f / / f}\right)$ (Fig. 7l).

\section{Targeting endosomal CGRP signaling provides superior relief of CGRP- and capsaicin-evoked PMA}

The finding that persistent GPCR signaling from endosomes mediates pain transmission suggests that GPCRs in endosomes rather than at the plasma membrane are a valid and perhaps superior target for the treatment of pain ${ }^{31,32,33}$. Nanoparticles have been used to deliver chemotherapeutics to tumor, 
where endocytosis and endosomal escape are necessary for drug delivery to cytosolic and nuclear targets ${ }^{41}$. The realization that GPCRs within endosomes are a therapeutic target, raises the possibility of exploiting the acid microenvironment of endosomes as a stimulus for nanoparticle disassembly and release of antagonist cargo ${ }^{32}$.

To target CLR in endosomes, we generated self-assembling soft polymer nanoparticles containing a CLR antagonist. Diblock copolymers were synthesized with a hydrophilic shell of P(PEGMA-co-DMAEMA) and a hydrophobic core of P(DIPMA-Co-DEGMA) (Fig. 8a). Gel permeation chromatography and ${ }^{1} \mathrm{H}$-nuclear magnetic resonance ( $\left.{ }^{1} \mathrm{H}-\mathrm{NMR}\right)$ confirmed the molecular weight and composition of nanoparticles (Supplementary Fig. 6a-d). Nanoparticles were self-assembled with MK-3207, a potent hydrophobic antagonist of human CLR/RAMP1, forming DIPMA-MK-3207 (Fig. 8a). Empty nanoparticles (DIPMA- $\varnothing$ ) were used as a control. Nanoparticles were uniformly spherical, with similar diameter (30-35 nm) and $\zeta-$ potential (-0.4-1.3 mV) (Fig. 8b,c). DIPMA nanoparticles demonstrate a pH-dependent cargo release at $\mathrm{pH}<\sim 6.5$, consistent with the protonation of the DIPMA tertiary amine $\left(\mathrm{pK}_{\mathrm{a}} 6.1\right)$, charge repulsion and disassembly ${ }^{32}$. DIPMA nanoparticles enter cells by clathrin- and dynamin-mediated endocytosis and disassemble in acidic early endosomes ${ }^{32}$. To determine whether DIPMA nanoparticles target endosomes containing CLR/RAMP1, HSCs expressing early endosomal antigen-1-GFP (EEA1-GFP) were incubated with DIPMA-Cy5 for 30 min to allow accumulation in EEA1-GFP+ve endosomes (Fig. 7d, Video S6). Cells were then incubated with TAMRA-CGRP, which was detected in endosomes containing Cy5-DIPMA within 5-10 min (Fig. 8d, Video S6). Thus, DIPMA nanoparticles accumulate with CLR/RAMP1 in early endosomes of Schwann cells.

To determine whether DIPMA-MK-3207 can antagonize CLR in endosomes, we measured CGRPstimulated CAMP formation using the CAMYEL CAMP BRET sensor, which detects total cellular CAMP. HEK293 cells expressing rat CLR/RAMP1 (HEK-rCRL/RAMP1) were preincubated with graded concentrations of DIPMA-MK-3207 or free MK-3207, DIPMA- $\varnothing$ or vehicle (control) for 30 min. Beginning at 0 min, baseline BRET was measured for 5 min, and cells were then challenged with CGRP. At 10 min, cells were washed to remove extracellular CGRP, and BRET was measured up to $35 \mathrm{~min}$. In vehicle-treated cells, CGRP stimulated a prompt increase in cAMP formation ( $1^{\text {st }}$ phase, 6-10 $\mathrm{min}$ ) that gradually declined after agonist removal from the extracellular fluid ( $2^{\text {nd }}$ phase, $11-35 \mathrm{~min}$ ) (Fig. 8e). DIPMA- $\varnothing$ did not affect this response. Free MK-3207 and DIPMA-MK-3207 (100, 316 nM) both inhibited CGRP-evoked cAMP in the $1^{\text {st }}$ phase to a similar extent (Fig. 8f). During the $2^{\text {nd }}$ phase, free MK-3207 was inactive at all concentrations whereas DIPMA-MK3207 (31.6, 100, $316 \mathrm{nM}$ ) strongly inhibited responses (Fig. 8g). The results suggest that DIPMA-MK3207 can antagonize the sustained phase of CGRP-stimulated formation of CAMP, which is attributable to endosomal CLR/RAMP1 signaling.

To assess antagonism of the pain signaling pathway in HSCs, we measured CGRP-evoked changes in $\mathrm{Ca}^{2+}$ response, which depend on endosomal CGRP signaling and activation of TRPA1. HSCs were preincubated with graded concentrations of DIPMA-MK-3207 or MK-3207 for 20 min to allow accumulation in endosomes, and washed to remove extracellular compounds. At 10 min after washing, 
cells were challenged with CGRP and $\mathrm{Ca}^{2+}$ response was measured as an index of TRPA1 activity. DIPMA-MK-3207 inhibited CGRP-evoked increase in $\mathrm{Ca}^{2+}$ response $\left(\mathrm{IC}_{50} 15.4 \mathrm{nM}, 95 \%\right.$ confidence interval, 10.9 - $21.0 \mathrm{nM}$ ) more potently than free MK-3207 (IC $502.9 \mu \mathrm{M}, 95 \%$ confidence interval, 1.9 - $4.2 \mu \mathrm{M}$, $\mathrm{P}<0.0001)$ (Fig. 8h). To assess antinociception, DIPMA-MK-3207 or free MK-3207 (0.1, 0.3, 1.0 pmol) was injected into the periorbital region 30 min before periorbital injection of CGRP or capsaicin. DIPMA-MK3207 (0.3, 1.0 pmol) more effectively inhibited PMA than the same doses of free MK-3207 (Fig. 8i). DIPMA- $\varnothing$ had no effect. Thus, endosomal targeting enhances the efficacy of a CLR/RAMP1 antagonist in a preclinical model of migraine pain.

\section{Discussion}

The major findings of the present study, supported by genetic and pharmacological evidence, are that CGRP causes migraine pain by activating CLR/RAMP1 of Schwann cells, CLR/RAMP1 signal from endosomes of Schwann cells to activate pain pathways, and endosomal CLR/RAMP1 can be targeted using nanoparticles and endocytosis inhibitors to relieve CGRP-evoked migraine pain. CLR/RAMP1 activation and trafficking to endosomes results in a persistent CAMP-dependent activation of NOS and generation of $\mathrm{NO}$, a mediator of migraine pain ${ }^{19}$. The role of NO in PMA is crucial, yet transient, as it is temporally limited to the engagement of TRPA1/NOX1, which releases ROS with a dual function. On one hand, ROS target TRPA1/NOX1 of Schwann cells to maintain ROS generation by a feed-forward mechanism. On the other hand, as suggested by experiments with selective TRPA1 deletion in primary sensory neurons, ROS target TRPA1 on nociceptors to signal allodynia to the CNS.

Periorbital capsaicin injection elicited acute nociception mediated by TRPV1 excitation and ensuing afferent discharge, which signals pain to the CNS. In a larger cutaneous area, capsaicin evoked delayed and prolonged PMA. While the acute pain response is most likely dependent on ion influx associated with TRPV1 activation, the mechanism underlying mechanical hypersensitivity 8,42 has remained elusive. Our findings support the existence of a paracrine mechanism that underlies PMA associated with neurogenic inflammation. We suggest that capsaicin locally activates TRPV1 + ve nerve fibers to generate action potentials that propagate antidromically into collateral fibers which release CGRP in a broader area, thus eliciting widespread PMA. PMA depends on the interaction between peptidergic nerve fibers, surrounding Schwann cells and nociceptive neurons that convey allodynic signals to the CNS. CGRP liberated from the varicosities of trigeminal TRPV1 + ve nerve fibers binds to CLR/RAMP1 of adjacent Schwann cells.

CGRP released from peptidergic $\mathrm{C}$-fibers has been hypothesized to target CLR/RAMP1 on adjacent non-

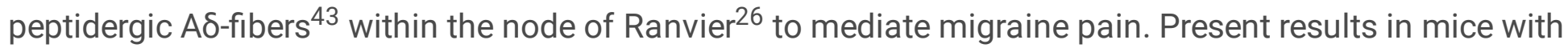
selective RAMP1 deletion in primary sensory neurons firmly support the view that nociceptors are not the target of CGRP to evoke PMA, which, instead, implicates the role of Schwann cells that wrap their terminals. A limitation of the present study is that we cannot distinguish between TRPV1-expressing nerve fibers that release CGRP and TRPA1-expressing nerve fibers that are targeted by Schwann cell ROS and convey allodynic signals centrally. Indeed, TRPV1 and TRPA1 may coexist in the same population of 
CGRP-expressing Aס- or C-fiber primary sensory neurons ${ }^{2,39}$. Most Schwann cells in Remak bundles contain multiple unmyelinated axons belonging to morphologically and functionally different neurons, including CGRP + ve and isolectin B4 + ve fibers ${ }^{44}$. Moreover, the bulk of CGRP is expressed in C-fiber nociceptors ${ }^{2}$. Thus, we cannot discriminate between the three possibilities that ROS from Schwann cells target TRPA1 on the same Aס- or C-fiber that releases CGRP, on a different C-fiber of the same Remak

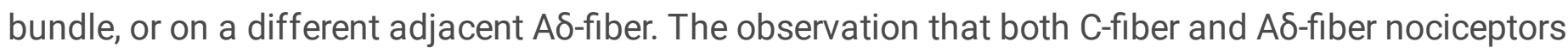
contribute to capsaicin-evoked hypersensitivity in humans ${ }^{45}$ supports the hypothesis that both types of neurons $^{26,43}$ are implicated in CGRP-mediated allodynia.

CLR/RAMP1 signals from endosomes by G-protein-mediated mechanisms that activate a subset of compartmentalized signals, including cytosolic protein kinase $\mathrm{C}$ and nuclear extracellular signal regulated kinase; these kinases regulate excitation of spinal neurons and pain transmission ${ }^{33}$. Our results show that CLR/RAMP1 activates $\mathrm{Ga}_{\mathrm{s}}, \mathrm{Ga}_{\mathrm{q}}$ and $\mathrm{Ga}_{\mathrm{i}}$ and recruits $\beta$ ARRs in endosomes of Schwann cells, determined by EbBRET. Inhibitors of clathrin- and dynamin-mediated endocytosis blocked the recruitment of CLR/RAMP1, Ga and $\beta A R R$ to endosomes, which presumably requires CLR/RAMP1 endocytosis. GPCR/Ga signaling complexes have also been detected in endosomes by using conformationally selective nanobodies ${ }^{46}$. The observation that endocytosis inhibitors attenuated CGRP-stimulated formation of CAMP and activation of NOS and TRPA1 reveals a central role for CLR/RAMP1 signaling in endosomes of Schwann cells in CGRP-evoked periorbital pain. Endocytosis of other Gs-coupled GPCRs is also necessary for the full repertoire of cAMP-mediated signaling outcomes, which entails endosomal recruitment of adenylyl cyclase $9^{47}$ and assembly of metastable accumulations of PKA ${ }^{48}$. We found that a nanoparticle-encapsulated CLR/RAMP1 antagonist, which targeted CLR/RAMP1 in endosomes and released cargo in the acidified endosomal microenvironment ${ }^{32}$, also attenuated CGRP-stimulated cAMP formation and blunted TRPA1 activation.

The observation that periorbital injection of inhibitors of clathrin and dynamin and of DIPMA-MK-3207 prevented CGRP- and capsaicin-evoked PMA provides the first evidence for a prominent role of endosomal CGRP signaling of pain from a peripheral site. The finding that nanoparticle encapsulation enhanced the potency of a CGRP antagonist for inhibition of endosomal signaling and resultant nociception supports the hypothesis that CLR/RAMP1 in endosomes is a target for migraine pain. Nanoparticle encapsulation similarly boosts the efficacy of an $\mathrm{NK}_{1}$ receptor antagonist in preclinical models of inflammatory and neuropathic pain ${ }^{32}$. An antagonist of CLR/RAMP1 conjugated to a membrane lipid cholestanol also accumulates in endosomes and provides superior relief from pain ${ }^{33}$, which reinforces the importance of CLR/RAMP1 endosomal signaling for pain transmission.

Limitations of the present study include uncertainty about the nature of the CLR/RAMP1 signaling complex in endosomes of Schwann cells, which warrants further investigation by proteomics approaches. Although some of the pharmacological inhibitors used to dissect the signaling pathway can have non-specific actions, we bolstered confidence in selectivity by using inhibitors of the same pathway and by genetic deletion of GPCRs and TRP channels. Our findings reveal a prominent role for 
CLR/RAMP1 in Schwann cells for CGRP-evoked periorbital pain. Future studies will investigate the role of this pathway in preclinical models of migraine pain.

Monoclonal antibodies to CGRP, although beneficial, are not effective in all patients ${ }^{11}$. While non-CGRPdependent mechanisms might explain this failure ${ }^{49}$, CGRP or CLR/RAMP1 antibodies likely do not inhibit CGRP signaling in endosomes. The small molecule CLR/RAMP1 antagonist, rimegepant, was found to resolve migraine attacks in patients treated with the anti-CLR/RAMP1 monoclonal antibody, erenumab ${ }^{50}$. This unexpected result was interpreted by the inherent membrane permeability of the lipophilic antagonist rimegepant ${ }^{51}$ that might favor inhibition of CGRP signaling in endosomes ${ }^{50}$, while neither receptor-targeted nor ligand-targeted monoclonal antibodies internalized with CLR/RAMP1 activated by CGRP ${ }^{52}$. Our results showing a superior inhibition of CGRP signaling in Schwann cells and of PMA by DIPMA-MK-3207, which selectively targets receptor activity in endosomes, reveals a better approach to control migraine pain. By inhibiting CLR/RAMP1 translocation to endosomes, inhibitors of clathrin- and dynamin-mediated endocytosis might offer an alternate therapeutic approach for migraine pain.

In 1936, Sir Thomas Lewis postulated ${ }^{1}$ that in human skin action potentials are carried antidromically from the injured nerve terminal to collateral branches from where a chemical substance is released that produces the flare and increases the sensitivity of other fibers responsible for pain. CGRP has been previously identified as the mediator responsible for neurogenic vasodilatation in rodents ${ }^{2}$, and in humans ${ }^{9}$. Herein, we propose that CGRP is the 'chemical substance' that, via the essential role of endosomal CLR/RAMP1, TRPA1/NOX1 and oxidative stress of surrounding Schwann cells, sustains the enhanced sensitivity of primary sensory neurons associated with neurogenic inflammation (Fig. 9). Results obtained in the two mouse models of migraine evoked by systemic CGRP or GTN suggest that the proalgesic pathway activated by CGRP in Schwann cells is implicated in migraine pain and is the target of peripherally acting anti-CGRP medicines.

\section{Methods}

\section{Experimental model and subject details}

Animals. Male mice were use throughout (25-30 g, 5-8 weeks). The following strains of mice were used C57BL/6J mice (Charles River, RRID:IMSR_JAX:000664); wild-type (Trpa ${ }^{+/+}$) and TRPA1-deficient

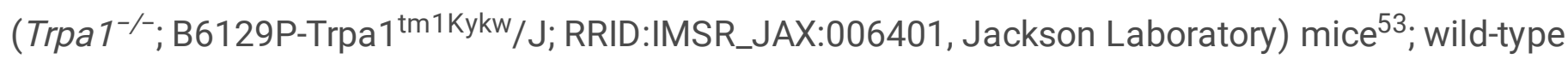

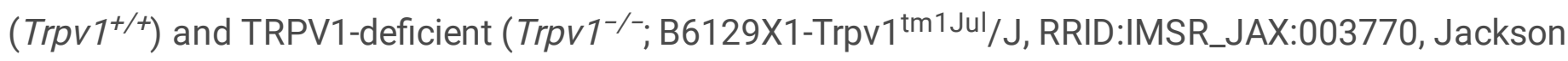
Laboratory) mice. Genetically modified mice were maintained as heterozygotes on a C57BL/6J background.

To generate mice in which the Trpa 1 and Ramp1 genes were conditionally silenced in Schwann cells/oligodendrocytes, homozygous 129S-Trpa $1^{\mathrm{tm} 2 \mathrm{Kykw}} / \mathrm{J}$ (floxed TRPA1, Trpa ${ }^{\text {fl/fl }}$, RRID:IMSR_JAX:008649 Jackson Laboratory) and C57BL/6N-Ramp1<tm1c(EUCOMM)Wtsi>/H (floxed Ramp1, 
Ramp $1^{f / f l}$ Stock No: EM:07401, MRC HARWELL Mary Lion Center $)^{54}$ were crossed with hemizygous B6.Cg-Tg(Plp1-Cre ${ }^{\text {ERT }}$ )3Pop/J mice (PIp1-Cre ${ }^{E R T}$, RRID:IMSR_JAX:005975 Jackson Laboratory), expressing a tamoxifen-inducible Cre in myelinating cells (PIp1, proteolipid protein myelin 1$)^{28}$. The progeny (Plp1-Cre ${ }^{E R T} ; \operatorname{Trpa} 1^{f / f l}$ and Ramp1-Cre $\left.{ }^{E R T} ; \operatorname{Trpa} 1^{f / / f f}\right)$ was genotyped by PCR for Trpa 1, Ramp1 and Plp1-Cre ${ }^{E R T}$. Mice negative for Plp1-Cre ${ }^{E R T}\left(P / p 1-C r e^{E R T} ;\right.$ Trpa $1^{f / f l}$ and Plp1-Cre ${ }^{E R T-;}$ Ramp $\left.1^{f / f f}\right)$ were used as control. Both positive and negative mice to $C r e^{E R T}$ and homozygous for floxed Trpa1 (Plp1-

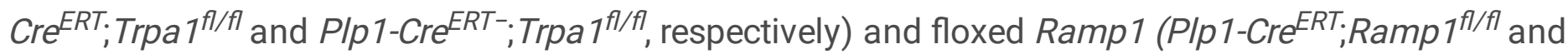
Plp1-Cre ${ }^{E R T-} ;$ Ramp $\left.1^{f / f f}\right)$ mice were treated with 4-hydroxytamoxifen (4-OHT) by subcutaneous periorbital (p.orb.) injection ( $0.02 \mathrm{mg} / 10 \mu \mathrm{l}$ in corn oil once a day for 3 consecutive days). Some Plp1$C r e^{E R T} ; R_{a m p} 1^{f l / f l}$ and $P / p 1-C r e^{E R T-} ; R a m p 1^{f l / f l}$ mice were treated with intraperitoneal (i.p.) 4-OHT (1 $\mathrm{mg} / 100 \mu \mathrm{l}$ in corn oil, once a day for 3 consecutive days).

Treatments resulted in Cre-mediated ablation of Trpa 1 and Ramp 1 in PLP-expressing Schwann cells/oligodendrocytes. To selectively delete the Trpa 1 and Ramp 1 gene in primary sensory neurons, $\operatorname{Trpa} 1^{f l} f f$ and $R a m p 1^{f / f l}$ mice were crossed with hemizygous Advillin-Cre mice (Adv-Cre) ${ }^{28,55,56}$. Both positive and negative mice to $C r e^{E R T}$ and homozygous for floxed $\operatorname{Trpa} 1$ ( $A d v-C r e^{+} ; T_{r p a}{ }^{f / / f l}$ and $A d v-$ $\mathrm{Cre}^{-} ; \operatorname{Trpa} 1^{f / f l}$, respectively) and floxed Ramp1 (Adv-Cre+;Ramp $1^{f / f l}$ and $\left.A d v-C r e^{-} ; R a m p 1^{f / f f}\right)$ were used.

The group size of $\mathrm{n}=8$ animals for behavioral experiments was determined by sample size estimation using $\mathrm{G}^{*}$ Power (v3.1) ${ }^{57}$ to detect size effect in a post-hoc test with type 1 and 2 error rates of 5 and $20 \%$, respectively. Mice were allocated to vehicle or treatment groups using a randomization procedure (http://www.randomizer.org/). Investigators were blinded to the identities (genetic background) and treatments, which were revealed only after data collection. No animals were excluded from experiments.

All behavioral experiments were in accordance with European Union (EU) guidelines for animal care procedures and the Italian legislation (DLgs 26/2014) application of the EU Directive 2010/63/EU. Study was approved by the Italian Ministry of Health (research permits \#383/2019-PR and \#765/2019-PR). The behavioral studies followed the animal research reporting in vivo experiment (ARRIVE) guidelines ${ }^{58}$. Mice were housed in a temperature- and humidity-controlled vivarium ( $12 \mathrm{hr}$ dark/light cycle, free access to food and water, 5 animals per cage). At least $1 \mathrm{hr}$ before behavioral experiments, mice were acclimatized to the experimental room and behavior was evaluated between 9:00 am and 5:00 pm. All the procedures were conducted following the current guidelines for laboratory animal care and the ethical guidelines for investigations of experimental pain in conscious animals set by the International Association for the Study of Pain ${ }^{59}$. Animals were anesthetized with a mixture of ketamine and xylazine $(90 \mathrm{mg} / \mathrm{kg}$ and 3 $\mathrm{mg} / \mathrm{kg}$, respectively, i.p.) and euthanized with inhaled $\mathrm{CO}_{2}$ plus $10-50 \% \mathrm{O}_{2}$.

Cell lines. Primary cultures of human Schwann cells (HSCs, \#1700, ScienCell Research Laboratories) were grown and maintained in Schwann cell medium (\#1701, ScienCell Research Laboratories) at $37^{\circ} \mathrm{C}$ in $5 \% \mathrm{CO}_{2}$ and $95 \% \mathrm{O}_{2}$. Cells were passaged at $90 \%$ confluency and discarded after 12 passages. HEK293T (\#CRL-3216 ${ }^{\mathrm{TM}}$, American Type Culture Collection) cells were cultured in Dulbecco's Modified Eagle's 
Medium (DMEM) supplemented with heat inactivated fetal bovine serum (FBS, 10\%), L-glutamine (2 mM), penicillin $(100 \mathrm{U} / \mathrm{ml})$ and streptomycin $(100 \mathrm{mg} / \mathrm{ml})$ at $37^{\circ} \mathrm{C}$ in $5 \% \mathrm{CO}_{2}$ and $95 \% \mathrm{O}_{2}$. The mouse Schwann cell line (IMS32 cells, \#PMC-SWN-IMS32-COS, Cosmo Bio USA) was grown and maintained in Schwann cell medium (\#PMC-SWN-MM-COS, Cosmo Bio USA) at $37^{\circ} \mathrm{C}$ in $5 \% \mathrm{CO}_{2}$ and $95 \% \mathrm{O}_{2}{ }^{60,61}$. All cells were used when received without further authentication.

Pharmacological reagents. Supplementary Tables 1 and 2 provide doses, routes of administration and concentrations and of all pharmacological reagents.

\section{Behavioral experiments}

Treatment protocol. Subcutaneous injections were made in the periorbital area 2-3 $\mathrm{mm}$ from the external eyelid corner ${ }^{17}$. Briefly, the mouse was lifted by the base of the tail and placed on a solid surface with one hand and the tail was pulled back. Then, it was quickly and firmly picked up by the scruff of the neck with the thumb and index finger of the other hand. Injection was made rapidly by a single operator with minimal animal restraint. Mice received unilateral (right side) injections $(10 \mu \mathrm{l} / \mathrm{site})$ of CGRP $(1.5 \mathrm{nmol}$ in $0.9 \% \mathrm{NaCl}), \mathrm{SP}(3.5 \mathrm{nmol}$ in $0.9 \% \mathrm{NaCl})$, capsaicin $(10,50,100 \mathrm{pmol}$ in $0.1 \%$ dimethyl sulfoxide, DMSO), or vehicles (control). Mice received bilateral injections $(10 \mu \mathrm{l} /$ site, right side same site as stimulus, left side symmetrical to right side) of antagonists and inhibitors. CGRP $(1.5 \mathrm{nmol}$ in $0.9 \% \mathrm{NaCl})$ or vehicle was also administered by intraplantar (i.pl., $20 \mu \mathrm{l} / \mathrm{site})$ or systemic $(0.1 \mathrm{mg} / \mathrm{kg}$, i.p.) injection. GTN was administered at $10 \mathrm{mg} / \mathrm{kg}$, i.p. injection.

Acute nociception. Immediately after the p.orb. injection, mice were placed inside a plexiglass chamber and spontaneous nociception was assessed for $10 \mathrm{~min}$ by measuring the time (s) that the animal spent rubbing the injected area of the face with its paws ${ }^{17,62}$.

Periorbital mechanical allodynia. PMA was assessed using the up-down paradigm ${ }^{63,64}$ in the same mice in which acute nociceptive responses were monitored. Briefly, mice were placed in a restraint apparatus designed for the evaluation of periorbital mechanical thresholds ${ }^{17}$. One day before the first behavioral observation, mice were habituated to the apparatus. PMA was evaluated in the periorbital region over the rostral portion of the eye (i.e., the area of the periorbital region facing the sphenoidal rostrum) ${ }^{65}$ before (basal threshold) and after $(0.5,1,2,4,6,8 \mathrm{hr})$ treatments. On the day of the experiment, after 20 min of adaptation inside the chamber, a series of 7 von Frey filaments in logarithmic increments of force $(0.02$, $0.04,0.07,0.16,0.4,0.6$ and $1.0 \mathrm{~g}$ ) were applied to the periorbital area perpendicular to the skin, with sufficient force to cause slight buckling, and held for approximately $5 \mathrm{~s}$ to elicit a positive response. Mechanical stimuli were applied homolaterally outside the periorbital area at a distance of 6-8 $\mathrm{mm}$ from the site where stimuli were injected. The response was considered positive by the following criteria: mouse vigorously stroked its face with the forepaw, head withdrawal from the stimulus, or head shaking. 
Mechanical stimulation started with the $0.16 \mathrm{~g}$ filament. Absence of response after $5 \mathrm{~s}$ led to the use of a filament with increased force, whereas a positive response led to the use of a weaker (i.e. lighter) filament. Six measurements were collected for each mouse or until four consecutive positive or negative responses occurred. The $50 \%$ mechanical withdrawal threshold (expressed in $\mathrm{g}$ ) was then calculated from these scores by using a $\delta$ value of 0.205 , previously determined.

Paw mechanical allodynia. Paw mechanical allodynia was evaluated by measuring the paw withdrawal threshold by using the up-down paradigm ${ }^{63,64}$. Mice were acclimatized ( $\left.1 \mathrm{hr}\right)$ in individual clear plexiglass boxes on an elevated wire mesh platform, to allow for access to the plantar surfaces of the hind paws. von Frey filaments of increasing stiffness $(0.07,0.16,0.4,0.6$ and $1.0,1.4$ and $2 \mathrm{~g})$ were applied to the hind paw plantar surfaces of mice with enough pressure to bend the filament. The absence of a paw being lifted after $5 \mathrm{~s}$ led to the use of the next filament with an increased force, whereas a lifted paw indicated a positive response, leading to the use of a subsequently weaker filament. Six measurements were collected for each mouse or until four consecutive positive or negative responses occurred. The $50 \%$ mechanical withdrawal threshold (expressed in $\mathrm{g}$ ) was then calculated.

Primary culture of mouse Schwann cells. Mouse Schwann cells (MSC) were isolated from sciatic nerves

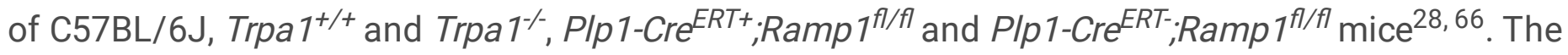
epineurium was removed, and nerve explants were divided into $1 \mathrm{~mm}$ segments and dissociated enzymatically using collagenase $(0.05 \%)$ and hyaluronidase $(0.1 \%)$ in Hank's Balanced Salt Solution (HBSS, $2 \mathrm{hr}, 37^{\circ} \mathrm{C}$ ). Cells were collected by centrifugation ( $800 \mathrm{rpm}, 10 \mathrm{~min}$, room temperature) and the pellet was resuspended and cultured in DMEM containing fetal calf serum (10\%), L-glutamine (2 mM), penicillin $(100 \mathrm{U} / \mathrm{ml})$, streptomycin $(100 \mathrm{mg} / \mathrm{ml})$, neuregulin $(10 \mathrm{nM})$ and forskolin $(2 \mu \mathrm{M})$. Three days later, cytosine arabinoside (Ara-C, $10 \mathrm{mM}$ ) was added to remove fibroblasts. Cells were cultured at $37^{\circ} \mathrm{C}$ in $5 \% \mathrm{CO}_{2}$ and $95 \% \mathrm{O}_{2}$. The culture medium was replaced every 3 days and cells were used after 15 days of culture.

qRT-PCR. Detailed method and the sets of primers for human and mouse cells are reported in Supplementary information and Table S3.

Calcium imaging. HSCs, MSCs and IMS32 cells were plated on poly-L-lysine-coated ( $8.3 \mu \mathrm{M}) 35 \mathrm{~mm}$ glass coverslips and maintained at $37^{\circ} \mathrm{C}$ in $5 \% \mathrm{CO}_{2}$ and $95 \% \mathrm{O}_{2}$ for $24 \mathrm{hr}$. Cells were loaded (40 min) with Fura-2 AM-ester $(5 \mu \mathrm{M})$ added to the buffer solution $\left(37^{\circ} \mathrm{C}\right.$ ) containing (in $\left.\mathrm{mM}\right) 2 \mathrm{CaCl}_{2} ; 5.4 \mathrm{KCl} ; 0.4$ $\mathrm{MgSO}_{4} ; 135 \mathrm{NaCl} ; 10 \mathrm{D}$-glucose; $10 \mathrm{HEPES}$ and bovine serum albumin (BSA, $0.1 \%$ ) at pH 7.4. Cells were 
exposed to CGRP $(0.01-10 \mu \mathrm{M})$ or vehicle $(0.9 \% \mathrm{NaCl})$ and the $\mathrm{Ca}^{2+}$ response was monitored for approximately $40 \mathrm{~min}$. In another set of experiments, IMS32 cells were exposed to AITC $(30 \mu \mathrm{M})$ or vehicle (0.03\% DMSO). The $\mathrm{Ca}^{2+}$ response to CGRP was monitored in the presence of CGRP8-37 (100

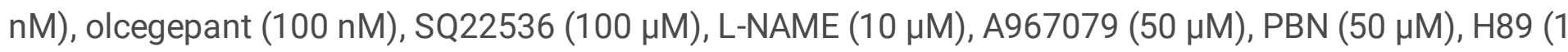
$\mu \mathrm{M}), \mathrm{ML} 171(1 \mu \mathrm{M})$ or vehicle (0.1\% DMSO), and also in the presence of DIPMA-MK-3207 (1-1000 nM) and MK-3207 free drug (0.01-1000 $\mu \mathrm{M})$ or DIPMA-empty. Some experiments used $\mathrm{Ca}^{2+}$-free buffer solution containing EDTA $(1 \mathrm{mM})$. Results were expressed as percent increase in ratio ${ }_{340 / 380}$ over baseline normalized to the maximum effect induced by ionomycin $(5 \mu \mathrm{M})$ added at the end of each experiment.

Protein extraction and western immunoblot assay. Detailed method is reported in Supplementary information.

In-cell ELISA assay. HSCs or IMS32 cells were plated in 96-well black wall clear bottom plates (Corning Life Sciences) $\left(5 \times 10^{5}\right.$ cells/well) and maintained at $37^{\circ} \mathrm{C}$ in $5 \% \mathrm{CO}_{2}$ and $95 \% \mathrm{O}_{2}$ for $24 \mathrm{hr}$. HSCs and IMS32 cells were exposed to CGRP ( 1 and $10 \mu \mathrm{M}$, respectively) or its vehicle (phosphate buffered saline, PBS) for $5,10,15,30$ and $60 \mathrm{~min}$, at $37^{\circ} \mathrm{C}$, then washed with DMEM pH 2.5 and fixed in $4 \%$ paraformaldehyde for $30 \mathrm{~min}$. Cells were then washed with TBST $(0.05 \%)$ and blocked with donkey serum (5\%) for $4 \mathrm{hr}$ at room temperature and incubated overnight $4{ }^{\circ} \mathrm{C}$ with eNOS ${ }^{\mathrm{pS} 1177}$ (\#ab184154, rabbit polyclonal, 1:100, Abcam). Cells were then washed and incubated with donkey anti-rabbit IgG conjugated with horseradish peroxidase (HRPO, 1:2000, Bethyl Laboratories Inc.) for $2 \mathrm{hr}$ at room temperature. Cells were then washed and stained using SIGMAFAST OPD for $30 \mathrm{~min}$ protected from light. After the incubation period, the absorbance was measured at $450 \mathrm{~nm}$. Change in NOS3 phosphorylation was calculated as a percentage of the signal in vehicle-treated cells.

CAMP ELISA assay. cAMP level was determined by the CatchPoint ${ }^{\text {TM }}$ cyclic-AMP fluorescent assay kit (\#R8088, Molecular Device) according to the manufacturer's protocol. Briefly, HSCs or IMS32 cells were plated in 96-well black wall clear bottom plates (Corning Life Sciences) $\left(5 \times 10^{5}\right.$ cells/well) and maintained in $5 \% \mathrm{CO}_{2}$ and $95 \% \mathrm{O}_{2}\left(24 \mathrm{hr}, 37^{\circ} \mathrm{C}\right)$. The cultured medium was replaced with HBSS added

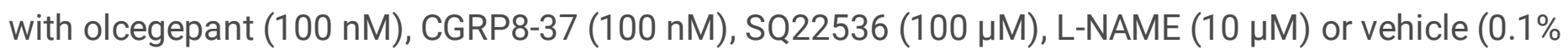
DMSO in HBSS) for 20 min at room temperature. HSCs or IMS32 cells were then stimulated with CGRP (1 and $10 \mu \mathrm{M}$, respectively), forskolin ( $1 \mu \mathrm{M}$, positive control) or their vehicles (HBSS) and maintained for 40 min at room temperature protected from light. Signal was detected $60 \mathrm{~min}$ after exposure to the stimuli. cAMP level was calculated using cAMP standards and expressed as nmol/1. 
Nitric oxide assay. Nitric oxide was determined by using the fluorometric-orange assay kit (\#ab219932, Abcam) according to the manufacturer's protocol. HSCs or IMS32 cells were plated 96-well black wall clear bottom plates (Corning Life Sciences) $\left(5 \times 10^{5}\right.$ cells/well) and maintained in $5 \% \mathrm{CO}_{2}$ and $95 \% \mathrm{O}_{2}$ $\left(24 \mathrm{hr}, 37^{\circ} \mathrm{C}\right)$. The cultured medium was replaced with Hanks' balanced salt solution (HBSS) added with

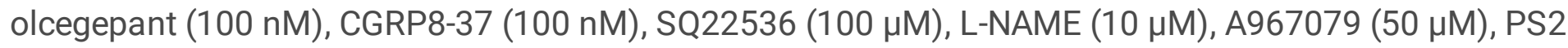
or Dy4 (both $30 \mu \mathrm{M})$, PS2 inact or Dy 4 inact $(30 \mu \mathrm{M})$ or vehicle $(0.1 \%$ DMSO in HBSS) for 20 min at room temperature. HSCs or IMS32 cells were then stimulated with CGRP ( 1 and $10 \mu \mathrm{M}$, respectively), diethylamine NONOate (1 mM, positive control) or their vehicles (HBSS) and maintained for $40 \mathrm{~min}$ at room temperature protected from light. Signal was detected $60 \mathrm{~min}$ after exposure to the stimuli. Change in nitric oxide level was calculated as percentage of the vehicle.

$\mathrm{H}_{2} \mathrm{O}_{2}$ assay. $\mathrm{H}_{2} \mathrm{O}_{2}$ was determined by using the Amplex Red assay (\#A12222, Thermo Fisher Scientific). Detailed method is reported in Supplementary information.

Immunofluorescence. Anesthetized mice were transcardially perfused with PBS and 4\% paraformaldehyde. Trigeminal and sciatic nerves were removed, postfixed for $24 \mathrm{hr}$, and paraffinembedded. Human and mouse formalin fixed paraffin embedded (FFPE) sections ( $5 \mu \mathrm{m})$ were incubated with primary antibodies: TRPA1 (\#ab58844, rabbit polyclonal, 1:400, Abcam), S100 (\#ab14849, mouse monoclonal [4B3], 1:300, Abcam), CLR (\#NLS6731, rabbit polyclonal, 1:30, Novus Biologicals), RAMP1 (\#ab241335, rabbit polyclonal, 1:200, Abcam), diluted in fresh blocking solution (PBS, pH 7.4, 2.5\% normal goat serum, [NGS]). Sections were then incubated with the fluorescent polyclonal secondary antibodies Alexa Fluor 488 and 594 (\#A32731, \#A32727 1:600; Invitrogen), and coverslipped using mounting medium with DAPI (Abcam). The Pearson correlation (Rcoloc) value for RAMP1 and S100 in the colocalization studies were calculated using the colocalization Plugin of the ImageJ software (ImageJ 1.32J, National Institutes of Health). The use of FFPE sections of human abdominal cutaneous tissues was approved by the Local Ethics Committee of the Florence University Hospital (Area Vasta Toscana Centro) (18271_bio/2020), according to the Helsinki Declaration, and informed consent was obtained.

CAMP CADDIS assay. HSCs were plated on poly-D-lysine-coated 96-well black wall clear bottom plates (Corning Life Sciences) $\left(25 \times 10^{3}\right.$ cells/well) and incubated in $5 \% \mathrm{CO}_{2}$ and $95 \% \mathrm{O}_{2}$ for $4-6 \mathrm{hr}$. HSCs were transduced with the baculovirus mediated Green Upward cADDIS cAMP reporter $(25 \mu \mathrm{l} /$ well, Montana Molecular) following manufacturer's instructions, and cells were incubated in $5 \% \mathrm{CO}_{2}$ and $95 \% \mathrm{O}_{2}$ (48 hr, $\left.37^{\circ} \mathrm{C}\right)$. HSCs were washed twice in HBSS plus HEPES $(10 \mathrm{mM}) \mathrm{pH}$ 7.4. Cells were incubated in 
HBSS/HEPES with the CLR/RAMP1 antagonists olcegepant (100 pM-100 $\mu \mathrm{M})$ or vehicle (control) for 30 min. Plates were mounted in a FlexStation3 plate reader (Molecular Devices) and fluorescence (485-500 excitation, 515-530 emission with cutoff at 510) was monitored. Baseline was measured for 1 min, and cells were stimulated with human CGRPa $(100 \mathrm{pM}-10 \mu \mathrm{M})$ or forskolin $(10 \mu \mathrm{M}$, positive control). For single cell imaging, HSCs were plated on poly-D-lysine-coated $35 \mathrm{~mm}$ glass bottom dishes (MatTek, Ashland) $\left(40 \times 10^{3}\right.$ cells/dish) and incubated in $5 \% \mathrm{CO}_{2}$ and $95 \% \mathrm{O}_{2}$ (overnight, $37^{\circ} \mathrm{C}$ ). HSCs cells were transduced with Green Upward cADDIS and incubated for $48 \mathrm{hr}$. HSCs were washed twice in HBSS/HBS and mounted on a Leica DMI8 microscope (Wetzlar, Germany). Fluorescence (470/40 excitation, 527/30 emission) was measured every $5 \mathrm{~s}$. Baseline was measured for $30 \mathrm{~s}$, and HSCs were challenged with human CGRPa (100 nM). Images were analyzed with ImageJ $(\mathrm{NIH})$. To inhibit endocytosis, cells were incubated in HBSS containing $0.45 \mathrm{M}$ sucrose or normal HBSS (control) for $30 \mathrm{~min}$ at $37^{\circ} \mathrm{C}$ before cAMP assays.

CAMYEL BRET CAMP assay. HEK293 cells stably expressing the CAMYEL BRET sensor $\left(\sim 2 \times 10^{6}\right)$ were seeded into $90 \mathrm{~mm}$ Petri dish (Corning ${ }^{\mathrm{TM}}$, USA) in DMEM/FBS/Geneticin and incubated in $5 \% \mathrm{CO}_{2}$ and $95 \% \mathrm{O}_{2}\left(24 \mathrm{hr}, 37^{\circ} \mathrm{C}\right)$. Prior to the transfection, the medium was changed to fresh

DMEM/FBS/Geneticin and rat CLR/RAMP1 was transfected (2.5 $\mu \mathrm{g}$ CLR/RAMP1 DNA/dish) using JetPEI (Polyplus Transfection, France) at a 1:6 ratio. After $24 \mathrm{hr}$, cells were plated in poly-L-lysine coated black 96 well CulturPlate (Perkin Elmer, USA) and incubated in $5 \% \mathrm{CO}_{2}$ and $95 \% \mathrm{O}_{2}\left(24 \mathrm{hr}, 37^{\circ} \mathrm{C}\right)$. BRET was assessed using a LUMIstar (BMG LABTECH, Germany). On the day of the assay, cells were equilibrated in HBSS for 30 min, supplemented with $12 \mathrm{mM} \mathrm{HEPES}$ at $37^{\circ} \mathrm{C}$ in $\mathrm{CO}_{2}$-free incubator. DIPMA-MK-3207 or free MK-3207 was incubated for $25 \mathrm{~min}$, followed by the addition of coelentrazine-h ( $50 \mu \mathrm{M})$ for $5 \mathrm{~min}$. Baseline was then measured for $5 \mathrm{~min}$, followed by stimulation with CGRP $\left(100 \mathrm{nM}, \sim \mathrm{EC}_{50}\right)$, vehicle (HBSS) or forskolin ( $1 \mu \mathrm{M}$, positive control), and further measurements for $5 \mathrm{~min}$. Buffer was then replaced by HBSS with coelentrazine-h $(50 \mu \mathrm{M})$ and measurements were resumed for further 25 min.

Synthesis of TAMRA-CGRP and endocytosis of TAMRA-CGRP and Cy5-DIPMA nanoparticles. Detailed method is reported in supplementary information.

EbBRET assays of $G$ protein and $\beta A R R$ recruitment to the plasma membrane and endosomes CDNAs. Detailed method is reported in supplementary information.

Synthesis and Characterization of Nanoparticles. Detailed method is reported in supplementary information. 
Statistical analysis. Results are expressed as mean \pm standard error of the mean (SEM). For multiple comparisons, a one-way analysis of variance (ANOVA) followed by the post-hoc Bonferroni's test or Dunnett's test was used. Two groups were compared using Student's t-test. For behavioral experiments with repeated measures, the two-way mixed model ANOVA followed by the post-hoc Bonferroni's test was used. Statistical analyses were performed on raw data using Graph Pad Prism 8 (GraphPad Software Inc.). $I_{50}$ values and confidence intervals were determined from non-linear regression models using Graph Pad Prism 8 (GraphPad Software Inc.). P values less than $0.05(P<0.05)$ were considered significant. Statistical tests used and the sample size for each analysis are listed in the Fig. legend.

Data Availability. Materials and data generated from this study are available upon request from Pierangelo Geppetti (geppetti@unifi.it) or Nigel W. Bunnett (nwb2@nyu.edu).

\section{Declarations}

\section{Acknowledgments}

Supported by grants from European Research Council (ERC) under the European Union's Horizon 2020 research and innovation programme (grant agreement No. 835286) (P.G.); National Institutes of Health (NS102722, DE026806, DK118971, DE029951, N.W.B., B.L.S.) and Department of Defense (W81XWH1810431, N.W.B., B.L.S.).

\section{Author Contributions}

F.D.L., R.N., A.H., L.L., D.D.J., R.L., J.D., M.M., D.S.M.d A., P.R-G, M.W., J.R., A.I., N.V., T.P.D., B.L.S., N.W.B., P.G., designed and conducted the experiments, performed the analysis, discussed the results, and wrote the paper.

\section{Competing interests statement}

N.W.B. is a founding scientist of Endosome Therapeutics Inc. P.G. is a member of the Scientific Advisory Board of Endosome Therapeutics Inc. R.N., F.D.L. and P.G. are founding scientists of FloNext Srl. P.G. has been in advisory boards and/or received fees for lectures from Novartis, Amgen, TEVA, AbbVie.

\section{References}

1. Lewis T. Experiments Relating to Cutaneous Hyperalgesia and Its Spread Through Somatic Nerves. Clin Sci 2, 373-414 (1936).

2. Russell FA, King R, Smillie SJ, Kodji X, Brain SD. Calcitonin gene-related peptide: physiology and pathophysiology. Physiol Rev 94, 1099-1142 (2014). 
3. Geppetti P, Holzer P. Neurogenic Inflammation. Boca Raton (1996).

4. Szallasi A, Blumberg PM. Vanilloid (Capsaicin) receptors and mechanisms. Pharmacol Rev 51, 159212 (1999).

5. Steinhoff MS, von Mentzer B, Geppetti P, Pothoulakis C, Bunnett NW. Tachykinins and their receptors: contributions to physiological control and the mechanisms of disease. Physiol Rev 94, 265-301 (2014).

6. La JH, Wang J, Bittar A, Shim HS, Bae C, Chung JM. Differential involvement of reactive oxygen species in a mouse model of capsaicin-induced secondary mechanical hyperalgesia and allodynia. Mol Pain 13, 1744806917713907 (2017).

7. Schmelz M, Luz O, Averbeck B, Bickel A. Plasma extravasation and neuropeptide release in human skin as measured by intradermal microdialysis. Neurosci Lett 230, 117-120 (1997).

8. Ali Z, Meyer RA, Campbell JN. Secondary hyperalgesia to mechanical but not heat stimuli following a capsaicin injection in hairy skin. Pain 68, 401-411 (1996).

9. Sinclair SR, et al. Inhibition of capsaicin-induced increase in dermal blood flow by the oral CGRP receptor antagonist, telcagepant (MK-0974). Br J Clin Pharmacol 69, 15-22 (2010).

10. Olesen J, et al. Calcitonin gene-related peptide receptor antagonist BIBN 4096 BS for the acute treatment of migraine. N Engl J Med 350, 1104-1110 (2004).

11. Ashina H. Migraine. N Engl J Med 383, 10 (2020).

12. Doods $H$, Arndt $K$, Rudolf $K$, Just $S$. CGRP antagonists: unravelling the role of CGRP in migraine. Trends Pharmacol Sci 28, 580-587 (2007).

13. Hostetler ED, et al. In vivo quantification of calcitonin gene-related peptide receptor occupancy by telcagepant in rhesus monkey and human brain using the positron emission tomography tracer [11C]MK-4232. J Pharmacol Exp Ther 347, 478-486 (2013).

14. Noseda R, et al. Fluorescently-labeled fremanezumab is distributed to sensory and autonomic ganglia and the dura but not to the brain of rats with uncompromised blood brain barrier. Cephalalgia 40, 229-240 (2020).

15. Mogil JS, et al. Variable sensitivity to noxious heat is mediated by differential expression of the CGRP gene. Proc Natl Acad Sci U S A 102, 12938-12943 (2005).

16. Rea BJ, et al. Peripherally administered calcitonin gene-related peptide induces spontaneous pain in mice: implications for migraine. Pain 159, 2306-2317 (2018).

17. De Logu F, et al. Migraine-provoking substances evoke periorbital allodynia in mice. $J$ Headache Pain 20, 18 (2019).

18. Marone IM, et al. TRPA1/NOX in the soma of trigeminal ganglion neurons mediates migraine-related pain of glyceryl trinitrate in mice. Brain 141, 2312-2328 (2018).

19. Ashina M, Hansen JM, BO AD, Olesen J. Human models of migraine - short-term pain for long-term gain. Nat Rev Neurol 13, 713-724 (2017).

20. Lipton RB, et al. Cutaneous allodynia in the migraine population. Ann Neuro/63, 148-158 (2008). 
21. Burstein R, Yarnitsky D, Goor-Aryeh I, Ransil BJ, Bajwa ZH. An association between migraine and cutaneous allodynia. Annals of Neurology 47, 614-624 (2000).

22. McLatchie LM, et al. RAMPs regulate the transport and ligand specificity of the calcitonin-receptorlike receptor. Nature 393, 333-339 (1998).

23. Lennerz JK, et al. Calcitonin receptor-like receptor (CLR), receptor activity-modifying protein 1 (RAMP1), and calcitonin gene-related peptide (CGRP) immunoreactivity in the rat trigeminovascular system: differences between peripheral and central CGRP receptor distribution. J Comp Neuro/ 507, 1277-1299 (2008).

24. Beckers HJ, Klooster J, Vrensen GF, Lamers WP. Ultrastructural identification of trigeminal nerve terminals in the pterygopalatine ganglion of rats: an anterograde tracing and immunohistochemical study. Brain Res 557, 22-30 (1991).

25. Cheng L, Khan M, Mudge AW. Calcitonin gene-related peptide promotes Schwann cell proliferation. $J$ Cell Biol 129, 789-796 (1995).

26. Edvinsson JCA, et al. C-fibers may modulate adjacent Adelta-fibers through axon-axon CGRP signaling at nodes of Ranvier in the trigeminal system. J Headache Pain 20, 105 (2019).

27. Toth CC, et al. Locally synthesized calcitonin gene-related Peptide has a critical role in peripheral nerve regeneration. J Neuropathol Exp Neurol 68, 326-337 (2009).

28. De Logu F, et al. Schwann cell TRPA1 mediates neuroinflammation that sustains macrophagedependent neuropathic pain in mice. Nat Commun 8, 1887 (2017).

29. De Logu F, et al. Peripheral Nerve Resident Macrophages and Schwann Cells Mediate Cancer-induced Pain. Cancer Res, (2021).

30. Abdo H, et al. Specialized cutaneous Schwann cells initiate pain sensation. Science 365, 695-699 (2019).

31. Jensen DD, et al. Neurokinin 1 receptor signaling in endosomes mediates sustained nociception and is a viable therapeutic target for prolonged pain relief. Sci Trans/ Med 9, (2017).

32. Ramírez-García PD, et al. A pH-responsive nanoparticle targets the neurokinin 1 receptor in endosomes to prevent chronic pain. Nat Nanotechnol 14, 1150-1159 (2019).

33. Yarwood RE, et al. Endosomal signaling of the receptor for calcitonin gene-related peptide mediates pain transmission. Proc Natl Acad Sci U S A 114, 12309-12314 (2017).

34. Talavera K, et al. Mammalian Transient Receptor Potential TRPA1 Channels: From Structure to Disease. Physiol Rev 100, 725-803 (2020).

35. Lassen LH, Haderslev P, Jacobsen VB, Iversen HK, Sperling B, Olesen J. CGRP may play a causative role in migraine. Cephalalgia 22, 54-61 (2002).

36. Guo S, et al. Selectivity of commonly used inhibitors of clathrin-mediated and caveolae-dependent endocytosis of G protein-coupled receptors. Biochimica et Biophysica Acta (BBA) - Biomembranes 1848, 2101-2110 (2015). 
37. Hosaka K, Rayner SE, von der Weid PY, Zhao J, Imtiaz MS, van Helden DF. Calcitonin gene-related peptide activates different signaling pathways in mesenteric lymphatics of guinea pigs. Am J Physiol Heart Circ Physiol 290, H813-822 (2006).

38. Miyamoto T, Dubin AE, Petrus MJ, Patapoutian A. TRPV1 and TRPA1 mediate peripheral nitric oxideinduced nociception in mice. PLoS One 4, e7596 (2009).

39. Bhattacharya MR, Bautista DM, Wu K, Haeberle H, Lumpkin EA, Julius D. Radial stretch reveals distinct populations of mechanosensitive mammalian somatosensory neurons. Proc Natl Acad Sci U $S A$ 105, 20015-20020 (2008).

40. De Logu F, et al. Schwann cells expressing nociceptive channel TRPA1 orchestrate ethanol-evoked neuropathic pain in mice. J Clin Invest 129, 5424-5441 (2019).

41. Farokhzad OC, Langer R. Impact of nanotechnology on drug delivery. ACS nano 3, 16-20 (2009).

42. LaMotte RH, Shain CN, Simone DA, Tsai EF. Neurogenic hyperalgesia: psychophysical studies of underlying mechanisms. J Neurophysio/ 66, 190-211 (1991).

43. Melo-Carrillo A, et al. Fremanezumab-A Humanized Monoclonal Anti-CGRP Antibody-Inhibits Thinly Myelinated (Adelta) But Not Unmyelinated (C) Meningeal Nociceptors. J Neurosci 37, 10587-10596 (2017).

44. Murinson BB, Hoffman PN, Banihashemi MR, Meyer RA, Griffin JW. C-fiber (Remak) bundles contain both isolectin B4-binding and calcitonin gene-related peptide-positive axons. J Comp Neurol 484, 392-402 (2005).

45. Ziegler EA, Magerl W, Meyer RA, Treede RD. Secondary hyperalgesia to punctate mechanical stimuli. Central sensitization to A-fibre nociceptor input. Brain 122 (Pt 12), 2245-2257 (1999).

46. Irannejad R, et al. Conformational biosensors reveal GPCR signalling from endosomes. Nature 495, 534-538 (2013).

47. Lazar AM, et al. G protein-regulated endocytic trafficking of adenylyl cyclase type 9. Elife 9, (2020).

48. Peng GE, Pessino V, Huang B, von Zastrow M. Spatial decoding of endosomal cAMP signals by a metastable cytoplasmic PKA network. Nat Chem Biol, (2021).

49. Olesen J, Burstein R, Ashina M, Tfelt-Hansen P. Origin of pain in migraine: evidence for peripheral sensitisation. Lancet Neuro/ 8, 679-690 (2009).

50. Mullin $\mathrm{K}$, et al. Potential for treatment benefit of small molecule CGRP receptor antagonist plus monoclonal antibody in migraine therapy. Neurology 94, e2121-e2125 (2020).

51. Luo G, et al. Discovery of (5S,6S,9R)-5-amino-6-(2,3-difluorophenyl)-6,7,8,9-tetrahydro-5Hcyclohepta[b]pyri din-9-yl 4-(2-oxo-2,3-dihydro-1 H-imidazo[4,5-b]pyridin-1-yl)piperidine-1-carboxylate (BMS-927711): an oral calcitonin gene-related peptide (CGRP) antagonist in clinical trials for treating migraine. J Med Chem 55, 10644-10651 (2012).

52. Manoukian R, Sun H, Miller S, Shi D, Chan B, Xu C. Effects of monoclonal antagonist antibodies on calcitonin gene-related peptide receptor function and trafficking. $J$ Headache Pain 20, 44 (2019). 
53. Kwan KY, et al. TRPA1 contributes to cold, mechanical, and chemical nociception but is not essential for hair-cell transduction. Neuron 50, 277-289 (2006).

54. Skarnes WC, et al. A conditional knockout resource for the genome-wide study of mouse gene function. Nature 474, 337-342 (2011).

55. Guan Z, et al. Injured sensory neuron-derived CSF1 induces microglial proliferation and DAP12dependent pain. Nat Neurosci 19, 94-101 (2016).

56. Zurborg S, et al. Generation and characterization of an Advillin-Cre driver mouse line. Mol Pain 7, 66 (2011).

57. Faul F, Erdfelder E, Lang AG, Buchner A. G*Power 3: a flexible statistical power analysis program for the social, behavioral, and biomedical sciences. Behav Res Methods 39, 175-191 (2007).

58. Kilkenny C, Browne WJ, Cuthill IC, Emerson M, Altman DG. Improving bioscience research reporting: the ARRIVE guidelines for reporting animal research. PLoS Bio/ 8, e1000412 (2010).

59. Zimmermann M. Ethical guidelines for investigations of experimental pain in conscious animals. Pain 16, 109-110 (1983).

60. Watabe K, Fukuda T, Tanaka J, Honda H, Toyohara K, Sakai O. Spontaneously immortalized adult mouse Schwann cells secrete autocrine and paracrine growth-promoting activities. J Neurosci Res 41, 279-290 (1995).

61. Watabe $\mathrm{K}$, et al. Tissue culture methods to study neurological disorders: establishment of immortalized Schwann cells from murine disease models. Neuropathology 23, 68-78 (2003).

62. Luccarini P, Childeric A, Gaydier AM, Voisin D, Dallel R. The orofacial formalin test in the mouse: a behavioral model for studying physiology and modulation of trigeminal nociception. $J$ Pain 7, 908914 (2006).

63. Dixon WJ. Efficient analysis of experimental observations. Annu Rev Pharmacol Toxicol 20, 441-462 (1980).

64. Chaplan SR, Bach FW, Pogrel JW, Chung JM, Yaksh TL. Quantitative assessment of tactile allodynia in the rat paw. J Neurosci Methods 53, 55-63 (1994).

65. Elliott MB, Oshinsky ML, Amenta PS, Awe 00, Jallo JI. Nociceptive neuropeptide increases and periorbital allodynia in a model of traumatic brain injury. Headache 52, 966-984 (2012).

66. Tao Y. Isolation and culture of Schwann cells. Methods Mol Biol 1018, 93-104 (2013).

\section{Figures}



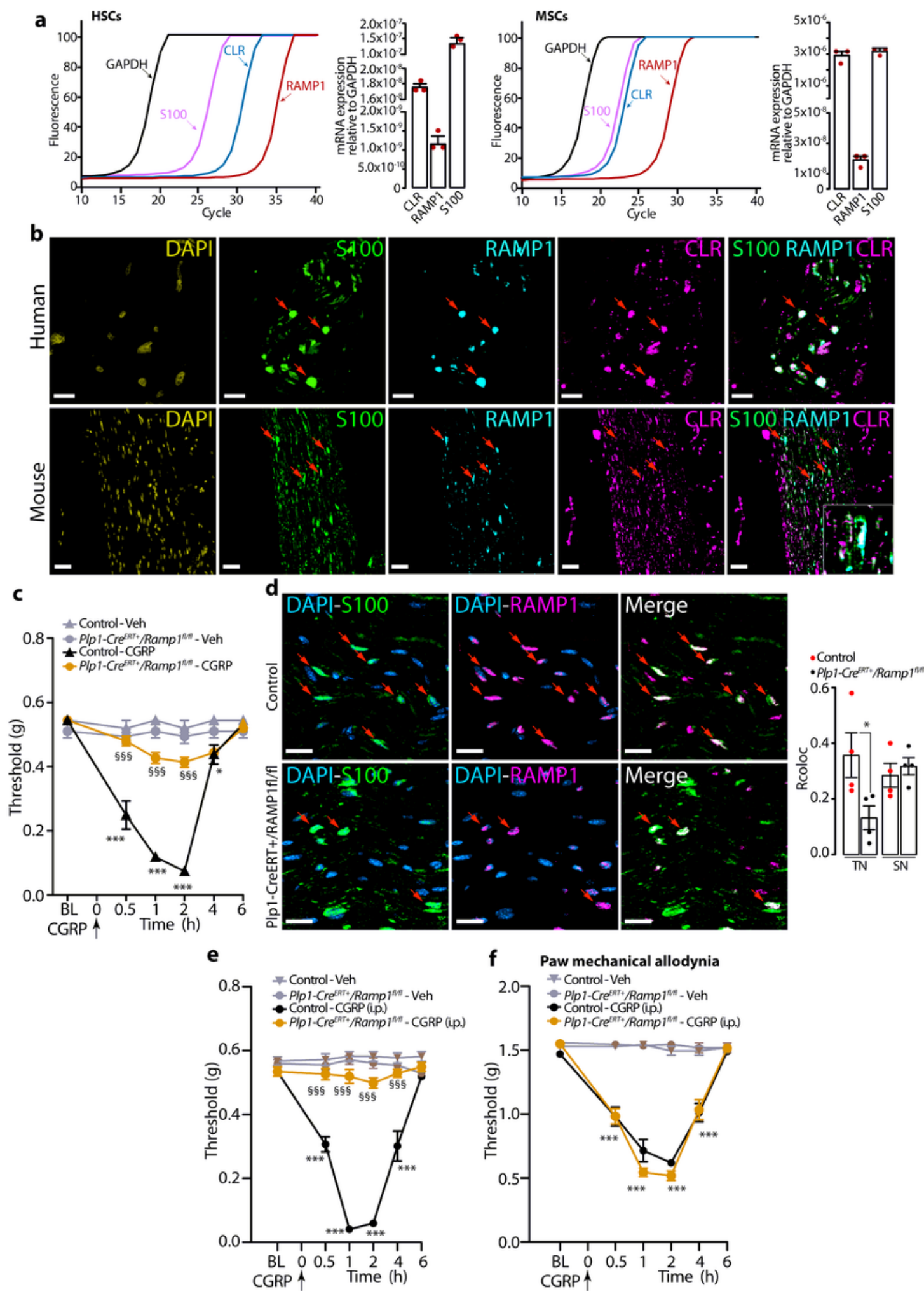

Figure 1

Schwann cell RAMP1 mediates PMA evoked by CGRP. (a) Representative real-time PCR plot and cumulative data for GAPDH, S100, CLR and RAMP1 mRNA in HSCs and MSCs ( $n=3$ independent experiments). (b) Representative images of DAPI and immunoreactive S100, RAMP1 and CLR in human and mouse cutaneous nerve bundles (scale, $10 \mu \mathrm{m}$ human, $50 \mu \mathrm{m}$ mouse) ( $\mathrm{n}=3$ subjects). (c) PMA induced by CGRP $(1.5 \mathrm{nmol})$ or vehicle in Plp1-CreERT+/Ramp1 fl/fl and Control mice $(\mathrm{n}=8$ mice per 
group) treated with periorbital 4-OHT. (d) Representative images and colocalization value (Rcoloc) of S100 and RAMP1 in periorbital nerve and sciatic nerve trunks from Plp1-CreERT+;Ramp1fl/fl and Control mice (scale: $20 \mu \mathrm{m}$ ) ( $\mathrm{n}=3$ replicates). TN (trigeminal nerve), SN (sciatic nerve). (e) PMA and (f) paw mechanical allodynia induced by intraperitoneal (i.p.) CGRP $(0.1 \mathrm{mg} / \mathrm{kg})$ or vehicle in Plp1CreERT+/Ramp1fl/fl and Control mice ( $\mathrm{n}=8$ mice per group) treated with periorbital 4-OHT. Mean \pm SEM. ${ }^{\star} P<0.05$, ${ }^{\star \star *} P<0.001$ vs. Control-Veh and TN-Control, $\S \S \S P<0.001$. vs. Control-CGRP. 2-way (c,e,f) or 1-way (d) ANOVA, Bonferroni correction.

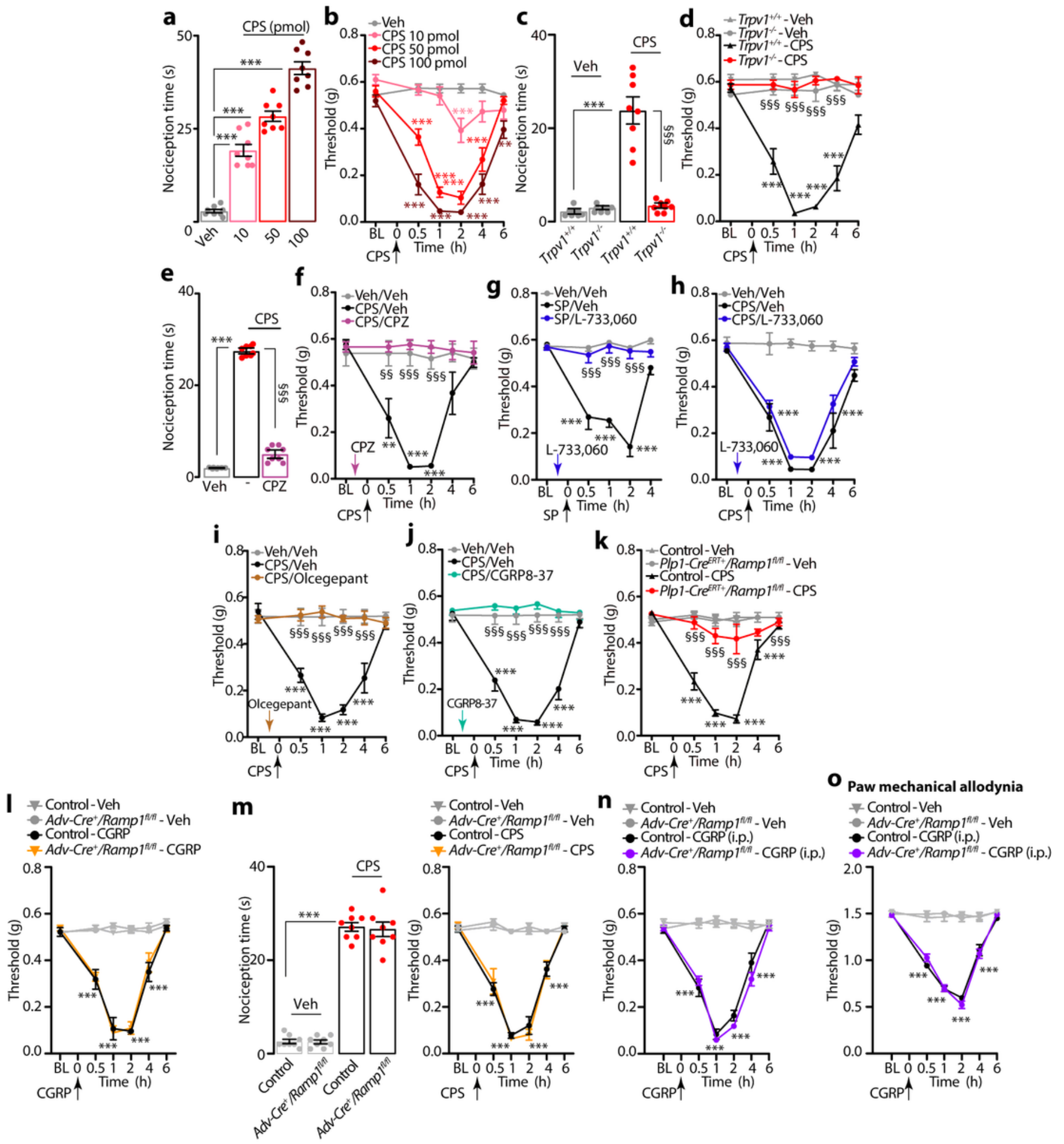




\section{Figure 2}

Capsaicin induces PMA via CGRP and CLR/RAMP1 in Schwann cells. (a) Acute nociception and (b) PMA after periorbital injection of capsaicin (CPS, 50 pmol) or vehicle in C57BL/6J mice. (c) Acute nociception and (d) PMA after CPS (50 pmol) or vehicle in Trpv1+/+ and Trpv1-/- mice. (e) Acute nociception and (f) PMA after CPS (50 pmol) or vehicle in C57BL/6J mice pretreated with capsazepine (CPZ, $100 \mathrm{pmol})$ or vehicle. $(\mathrm{g}, \mathrm{h})$ PMA after periorbital SP $(3.5 \mathrm{nmol}), \mathrm{CPS}(50 \mathrm{pmol})$ or vehicle in C57BL/6J mice pretreated $(0.5 \mathrm{~h})$ with L-733,060 (20 nmol) or vehicle. (i, j) PMA after CPS (50 pmol) or vehicle in C57BL/6J mice pretreated $(0.5 \mathrm{~h})$ with olcegepant $(1 \mathrm{nmol})$ or CGRP8-37 $(10 \mathrm{nmol})$ or vehicle. (k) PMA after CPS (50 $\mathrm{pmol}$ ) or vehicle in PIp1-CreERT+/Ramp1fl/fl or Control mice treated with periorbital 4-OHT or vehicle. (I) PMA after periorbital CGRP $(1.5 \mathrm{nmol})$ or vehicle and $(\mathrm{m})$ acute nociceptive response and PMA after periorbital CPS (50 pmol) or vehicle in Adv-Cre+/Ramp1fl/fl or Control mice. (n) PMA and (o) paw mechanical allodynia induced by intraperitoneal (i.p.) CGRP $(0.1 \mathrm{mg} / \mathrm{kg})$ or vehicle in AdvCre+/Ramp1fl/fl or Control mice. Mean $\pm S E M ., n=8$ mice per group. ${ }^{* \star} P<0.01,{ }^{\star * *} P<0.001$ vs. Veh/Veh, Trpv1+/+-Veh and Control-Veh; §§P<0.01, §§§P<0.001 vs. Trpv1+/+-CPS, CPS/Veh, SP/Veh, Control-CPS, Control-CGRP. 1-way (a, c, e and $m$ left panel) or 2-way (b, $d, f-I, m$ right panel and $n, 0)$ ANOVA, Bonferroni correction. 
a

- Control-Veh/Neh

$\checkmark$ Adv-Cre $^{+} /$Ramp $^{1 / t / 1}-$ Veh/Veh

- Control-GTN/Veh

- Adv-Cre+/Ramp 1 ${ }^{f / r}$ - GTNNeh

- Control-GTN/Olcegepant

- Adv-Cre $/$ Ramp $^{1 / H}$ - GTN/Olcegepant

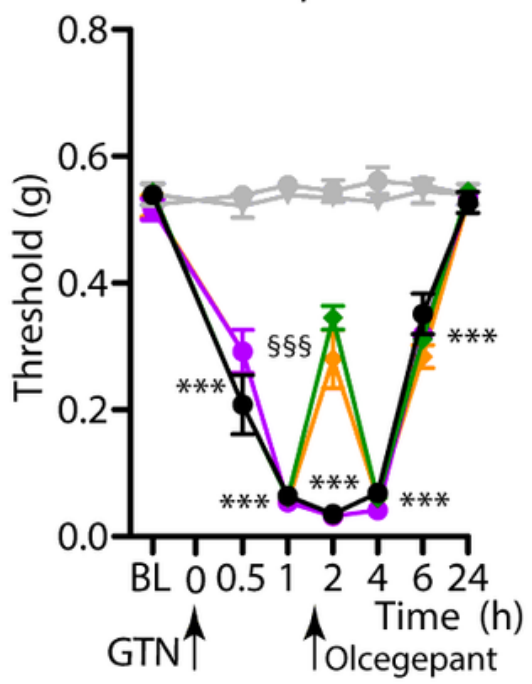

C

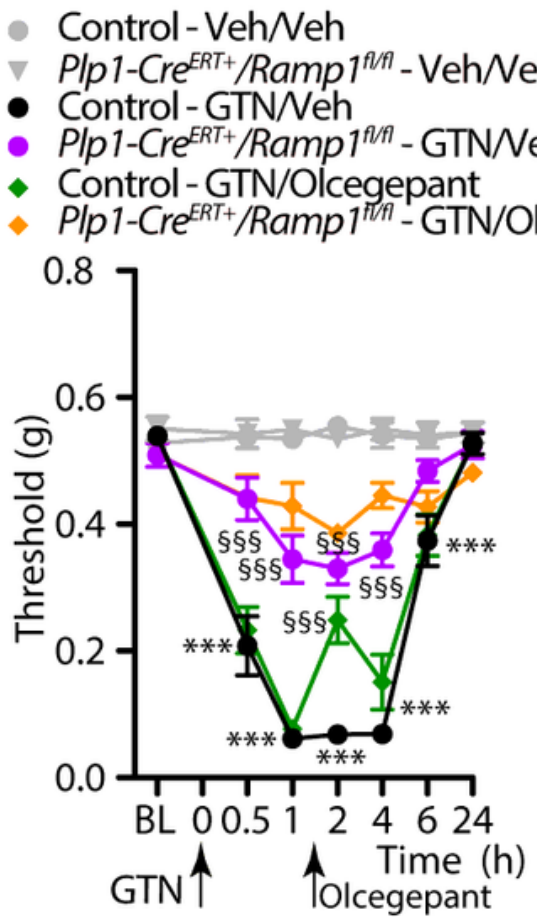

b Paw mechanical allodynia

- Control-Veh/Neh

V Adv-Cre $/$ Ramp ${ }^{t / f t}-$ Veh/Neh

- Control-GTNNeh

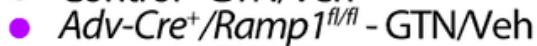

- Control-GTN/Olcegepant

- Adv-Cre $/ R a m p 1^{t / h}-$ GTN/Olcegepant

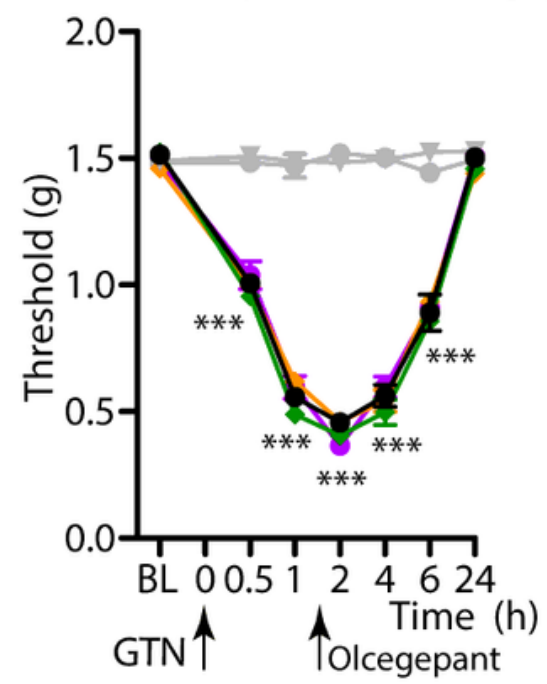

d Paw mechanical allodynia

Control-Veh/Neh

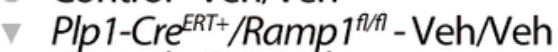

- Control-GTN/Neh

- Plpi-Cre $e^{E R T} / R a m p 1^{f / T}$ - GTN/Neh

- Control-GTN/Olcegepant

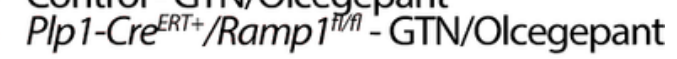

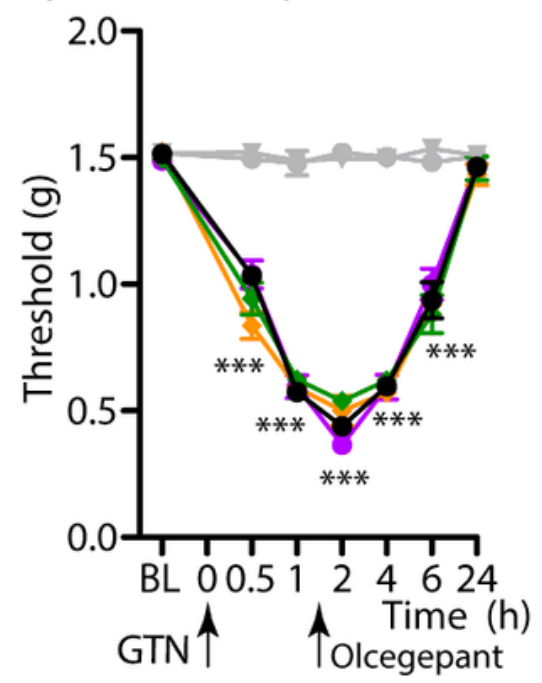

Figure 3

GTN induces PMA via CGRP released from periorbital trigeminal terminals and, CLR/RAMP1 in Schwann cells. (a) PMA and (b) paw mechanical allodynia induced by intraperitoneal (i.p.) GTN (10 mg/ $\mathrm{kg}$ ) or vehicle in Adv-Cre+/Ramp1 fl/fl or Control mice post-treated (1.5 hs after GTN) with olcegepant (1 nmol) or vehicle. (c) PMA and (d) paw mechanical allodynia induced by GTN $(10 \mathrm{mg} / \mathrm{kg}$, i.p.) or vehicle in Plp1CreERT+/Ramp1fl/fl or Control (treated with periorbital 4-OHT or vehicle) post-treated (1.5 hs after GTN) 
with olcegepant $(1 \mathrm{nmol})$ or vehicle. Mean $\pm S E M ., \mathrm{n}=8$ mice per group. ${ }^{\star} * \star \mathrm{P}<0.001$ vs. Control-Veh/Veh; $\S \S \S P<0.001$ vs. Control-GTN/Veh. 2-way ANOVA, Bonferroni correction.
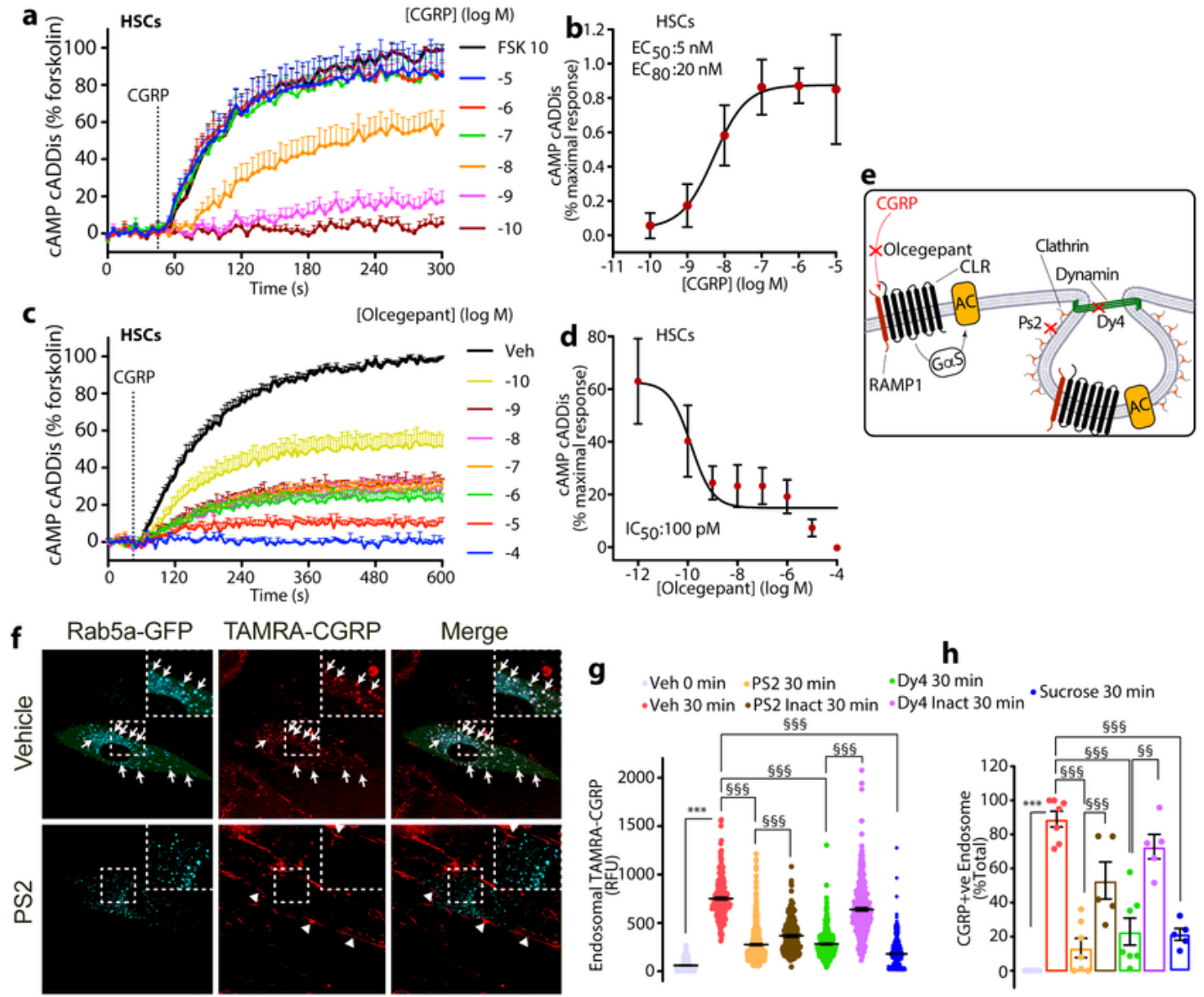

\section{h}
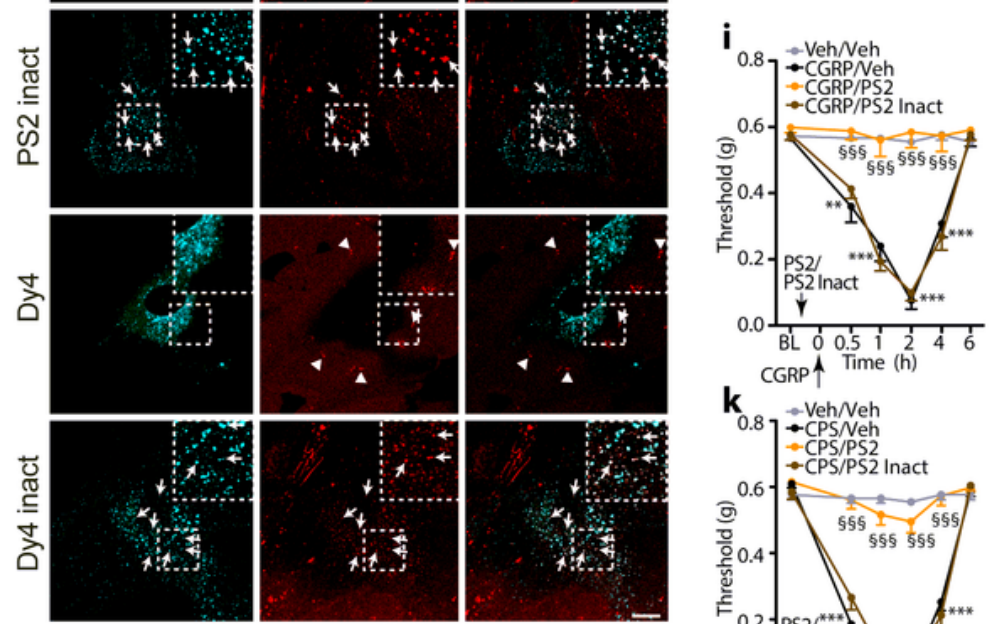

y $30 \mathrm{~min}$

$30 \min \cdot$ Sucrose $30 \mathrm{~min}$
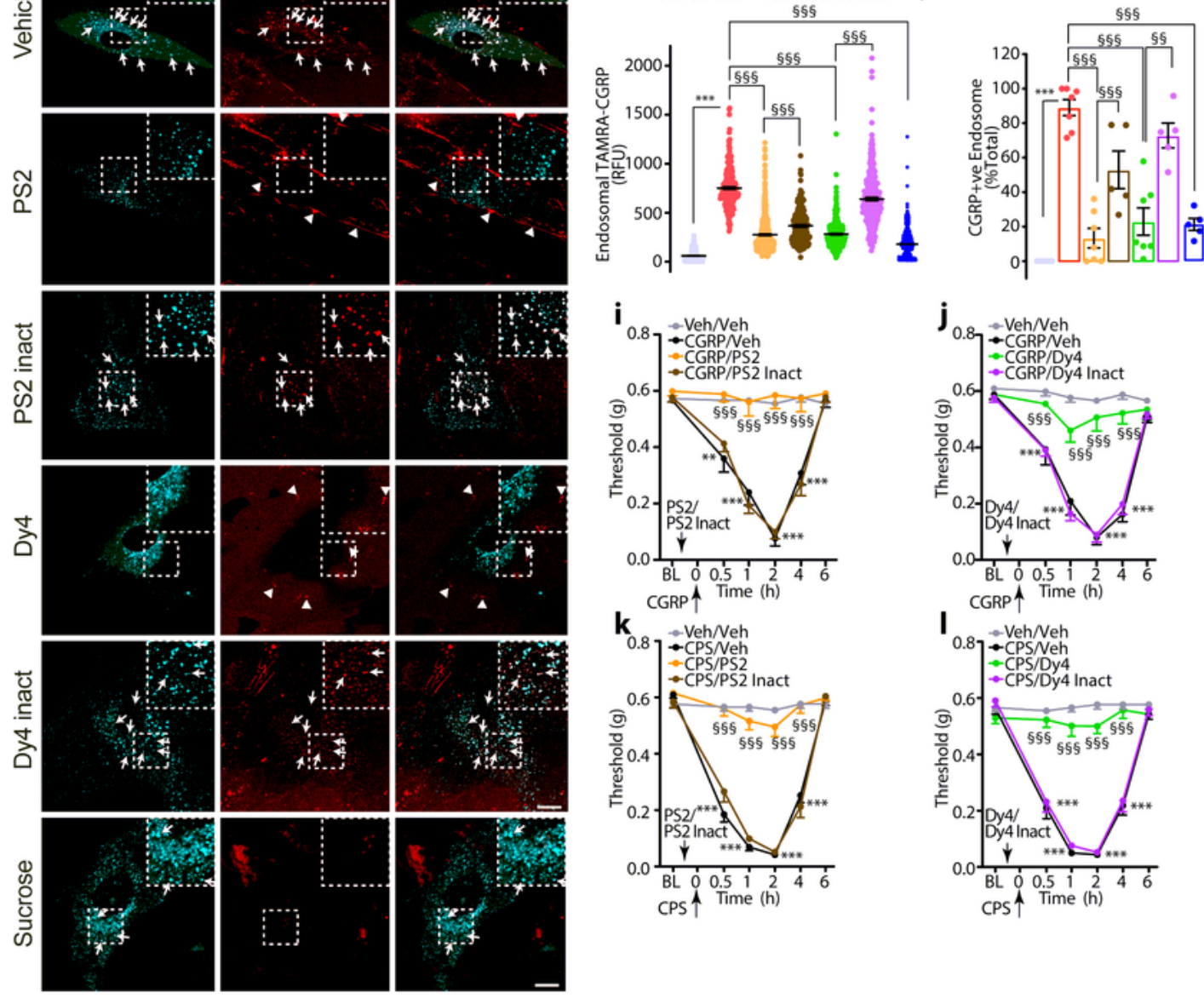

\section{Figure 4}

Functional CLR/RAMP1 is expressed by HSCs and undergoes clathrin- and dynamin-mediated endocytosis, which underlies nociception. $(a, b)$ Effects of graded concentrations of CGRP on cAMP formation. (c, d) Effects of graded concentrations of olcegepant on CGRP (100 nM)-evoked cAMP 
formation. (e) Pharmacological targets. (f) Representative images of HSCs expressing Rab5a-GFP at 30 min after incubation with TAMRA-CGRP (100 nM). Arrows denote colocalization of TAMRA-CGRP and Rab5a-GFP. Arrowheads denote retention of a weak TAMRA-CGRP signal at the plasma membrane. Cells were preincubated with vehicle, Dyngo-4a (Dy4), Pitstop 2 (PS2), inactive analogs (PS2 and Dy4 inact) (all $30 \mu \mathrm{M}$ ) or sucrose $(0.45 \mathrm{M})$. ( $\mathrm{n}=4$ independent experiments). Scale: $10 \mu \mathrm{m}$. ( $\mathrm{g}, \mathrm{h})$ Quantification of localization of TAMRA-CGRP in endosomes (g) and of the number of TAMRA-CGRP+ve endosomes (h). ( $\mathrm{n}=5-7$ independent experiments, 5 cells imaged per experiment). (I-L) PMA induced by periorbital CGRP $(1.5 \mathrm{nmol})(\mathrm{l}, \mathrm{J})$ or capsaicin (CPS, $50 \mathrm{pmol})(\mathrm{k}, \mathrm{l})$ or vehicle in C57BL/6J mice pretreated $(0.5 \mathrm{~h})$ with PS2, Dy4, PS2 or Dy4 inact (all $500 \mathrm{pmol}$ ) ( $\mathrm{n}=8$ mice per group). Mean $\pm S E M$. $\star \star * P<0.01,{ }^{\star} \star \star * P<0.001$ vs. Veh 0 min, and Veh/Veh; $\S \S P<0.01$, $\S \S \S<<0.001$ vs. Veh $30 \mathrm{~min}, \mathrm{PS} 230 \mathrm{~min}$, Dy4 $30 \mathrm{~min}, \mathrm{CGRP} / \mathrm{PS} 2$ inact, CGRP/Dy4 inact, CPS/PS2 inact, CPS/Dy4 inact. 1-way (h, i) or 2-way (j-m) ANOVA, Bonferroni correction. 


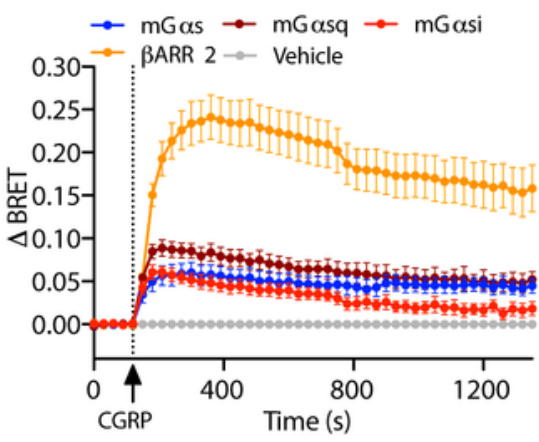

e HSC-hCLR/RAMP1, RGFP-CAAX

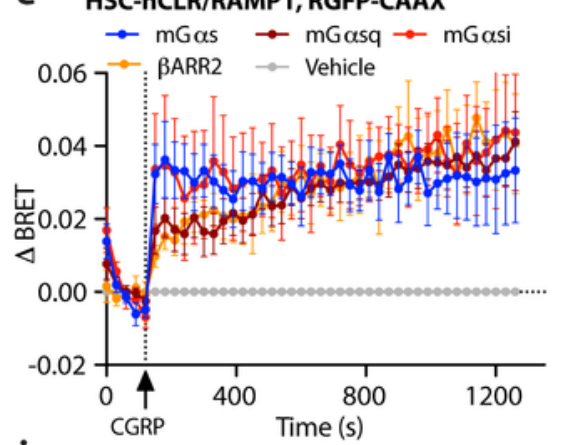

i HEK-hCLR-Rluc8/RAMP1, tdRGFP-Rab5a j

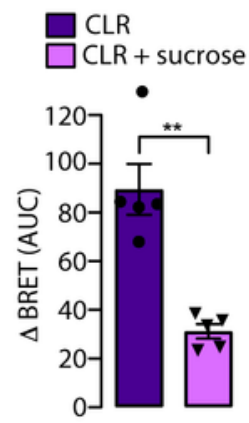

b HEK-hCLR/RAMP1,RGFP-CAAX C

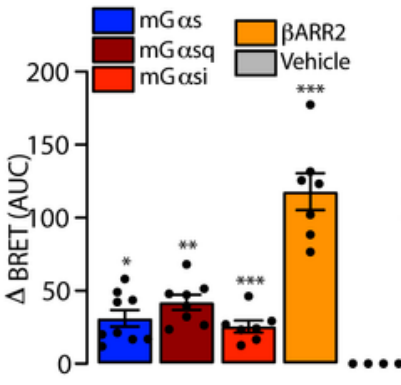

f $_{\text {HSC-hCLR/RAMP1, RGFP-CAAX }}$

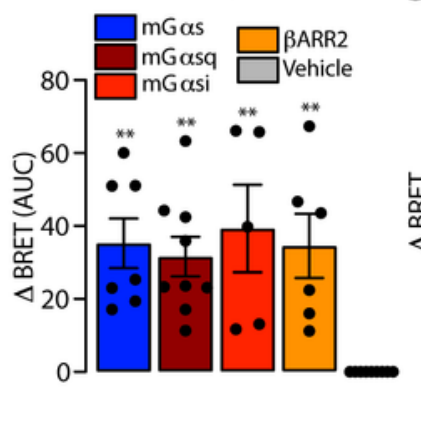

HEK-hCLR/RAMP1, tdRGFP-Rab5a

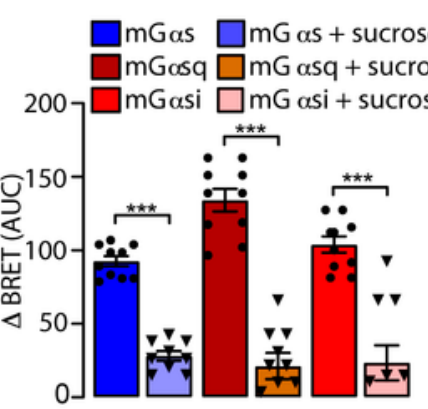

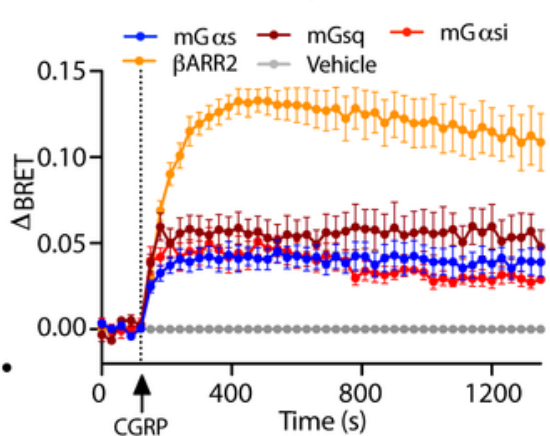

9 HSC-hCLR/RAMP1, tdRGFP-Rab5a

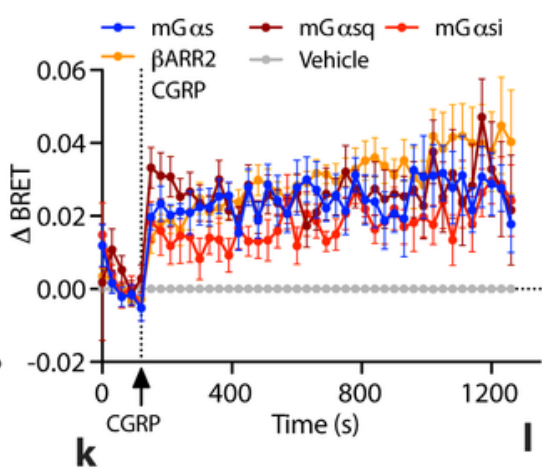

HEK-hCLR/RAMP1, tdRGFP-Rab5a

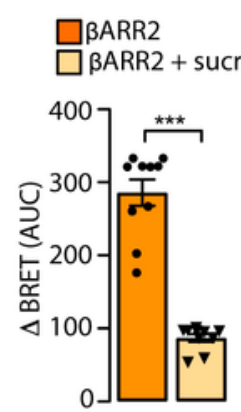

HSC

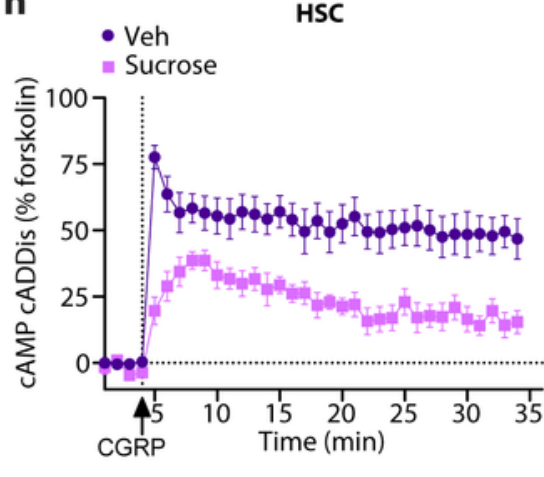

d HEK-hCLR/RAMP1, tdRGFP-Rab5a

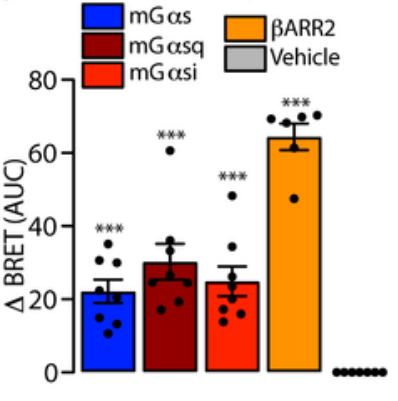

h HSC-hCLR/RAMP1, tdRGFP-Rab5a

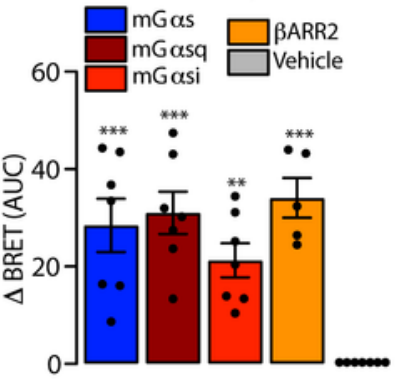

HSC-hCLR/RAMP1, tdRGFP-Rab5a

$\square$ mGas $\square$ mGas + sucrose

$\square$ mGasq $\square$ mGasq + sucrose

$\square$ mGasi $\square$ mGasi + sucrose

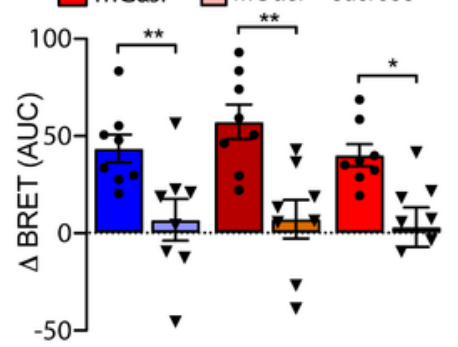

HSC

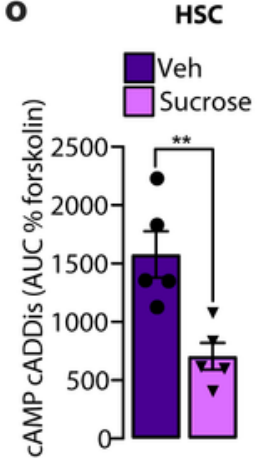

Figure 5

CGRP leads to Ga protein activation and $\beta A R R 2$ recruitment at the plasma membrane and in early endosomes in HEK-hCLR/RAMP1 cells and HSCs-hCLR/RAMP1. Endosomal signaling generates sustained formation of cAMP in HSCs. (a-d) CGRP (100 nM) increased EbBRET between Rluc8-mGas, Rluc8-mGasq, Rluc8-mGasi, and Rluc2-ßARR2 with RGFP-CAAX (a, b) and tdRGFP-Rab5a (c, d) in HEKhCLR/RAMP1 cells. a, c time course. b, d area under curve (AUC). (E-H) CGRP (100 nM) increased EbBRET 
between Rluc8-mGas, Rluc8-mGasq, Rluc8-mGasi, and Rluc2-ßARR2 with RGFP-CAAX (e, f) and tdRGFPRab5a $(\mathrm{g}, \mathrm{h})$ in HSC-hCLR/RAMP1 cells. e, g time course. f, h AUC. (i) Hypertonic sucrose (0.45 M) inhibited CGRP (100 nM)-stimulated EbBRET between hCLR-Rluc8 and tdRGFP-Rab5a in HEKhCLR/RAMP1 cells. (j, k) Hypertonic sucrose (0.45 M) inhibited CGRP (100 nM)-stimulated EbBRET between Rluc8-mGas, Rluc8-mGasq, Rluc8-mGasi and Rluc2-ßARR2 with tdRGFP-Rab5a in HEKhCLR/RAMP1 cells. (l, m) Sucrose (0.45 M) inhibited CGRP (100 nM)-stimulated EbBRET between Rluc8mGas, Rluc8-mGasq, Rluc8-mGasi, and Rluc2-ßARR2 with tdRGFP-Rab5a in HSC-hCLR/RAMP1 cells. (n, o) Sucrose (0.45 M) inhibited CGRP (100 nM)-stimulated formation of cAMP in HSCs. n, time course. o, AUC. Mean \pm SEM. ( $n=5-10$ independent experiments). ${ }^{*} P<0.05,{ }^{*} P<0.01,{ }^{*} *{ }^{*} P<0.001$, vs. Veh. 1-way ANOVA, Dunnett's correction $(b, d, f, h)$ or parametric unpaired t test $(i-m, o)$. 

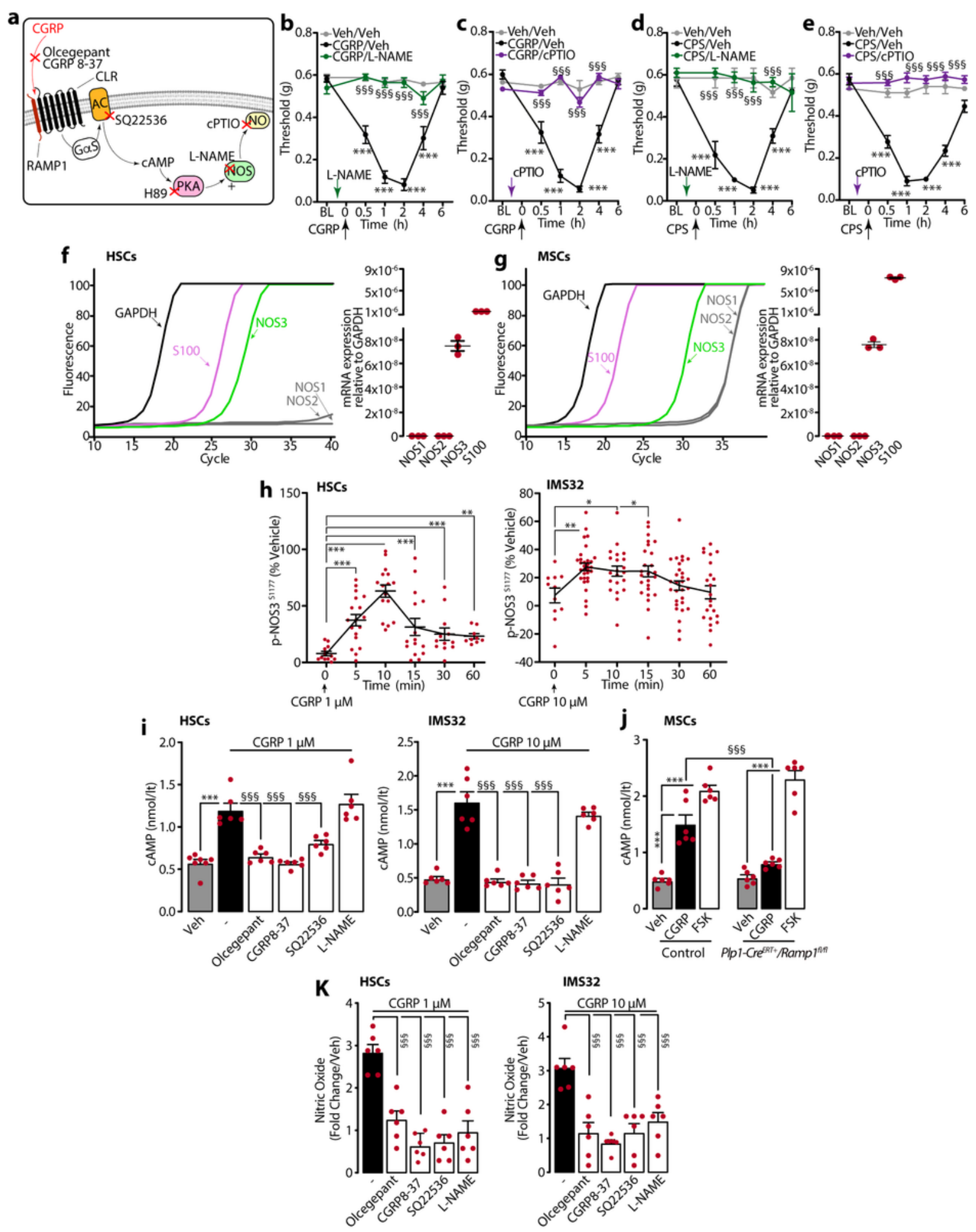

\section{Figure 6}

Endogenous and exogenous CGRP induces PMA via NO production. (a) Pharmacological targets. (b-e) PMA after periorbital injection of CGRP (1.5 nmol), capsaicin (CPS, $50 \mathrm{pmol})$ or vehicle in C57BL/6J mice pretreated $(0.5 \mathrm{~h})$ with L-NAME $(1 \mu \mathrm{mol})$ and $\mathrm{cPTIO}(200 \mathrm{nmol})$ or vehicle $(\mathrm{n}=8$ mice per group). $(\mathrm{f}, \mathrm{g})$ Realtime PCR plot and cumulative data for GAPDH, S100, NOS1, NOS2 and NOS3 in primary HSCs and MSCs ( $n=3$ independent experiments). (h) In-cell p-NOS3s1177 ELISA in HSCs and IMS32 cells before (0) or 
after CGRP $(1 \mu \mathrm{M})(\mathrm{n}=4$ independent experiments). cAMP assay in (i) HSCs, IMS32 and (j) MSCs from Plp1-CreERT+/Ramp1fl/fl or Control mice treated with intraperitoneal 4-OHT (k) nitric oxide assay in HSCs and IMS32 cells treated with CGRP $(1 \mu \mathrm{M})$ or vehicle. Some cells were treated with olcegepant $(1 \mu \mathrm{M})$, CGRP8-37 $(1 \mu \mathrm{M})$, SQ22536 $(100 \mu \mathrm{M})$, L-NAME $(100 \mu \mathrm{M})$ or vehicle ( $\mathrm{n}=3$ independent experiments). Mean $\pm S E M$. (-) represents the combination of different vehicles. ${ }^{\star} P<0.05,{ }^{*} P<0.01,{ }^{\star} * \star P<0.001$ vs. Veh/Veh, time 0 (min); $\S \S \S P<0.001$ vs. CGRP/Veh, CGRP $1 \mu \mathrm{M}$ and $10 \mu \mathrm{M}$. 1-way (h-k) or 2-way (b-e) ANOVA, Bonferroni correction.
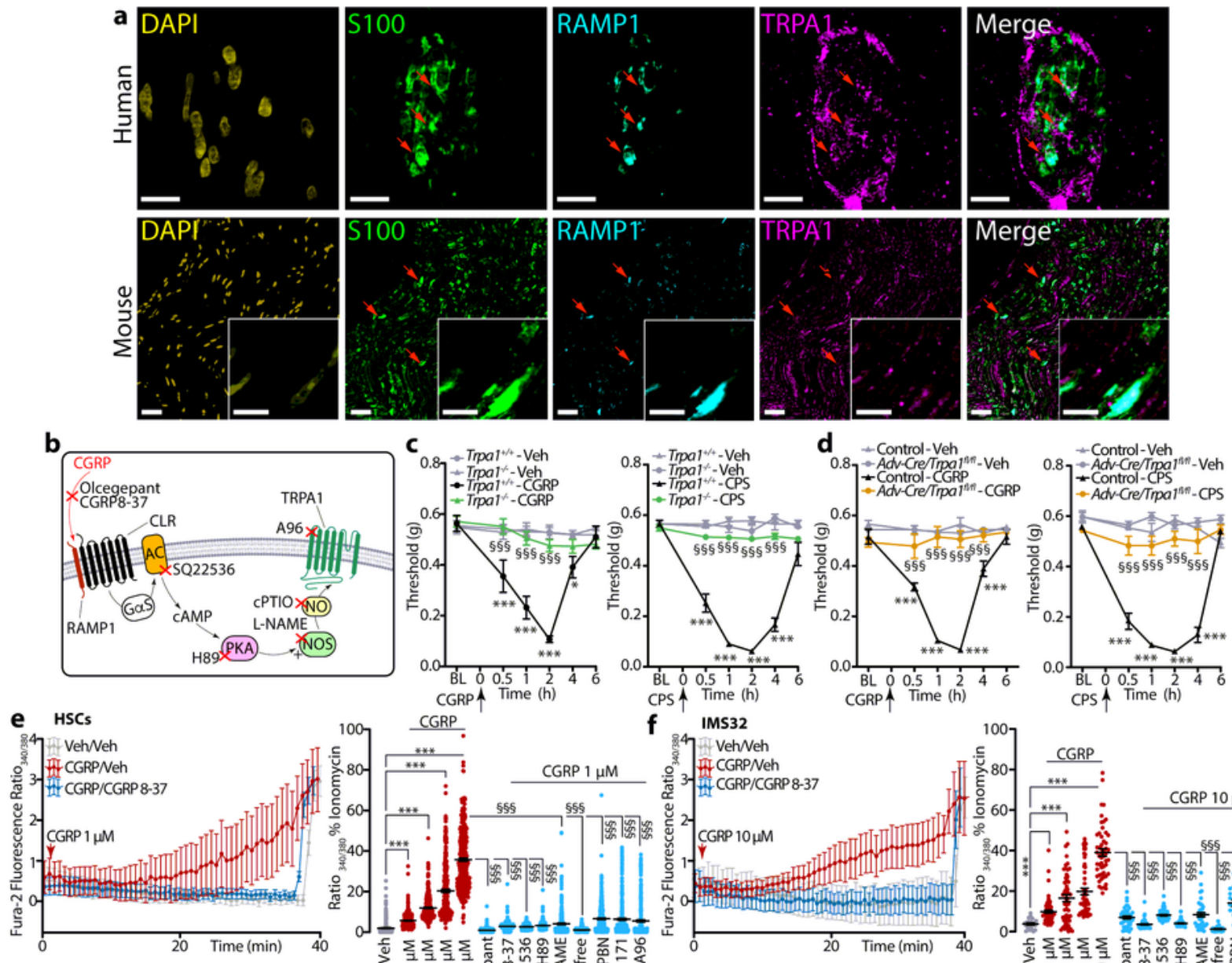
CGRP
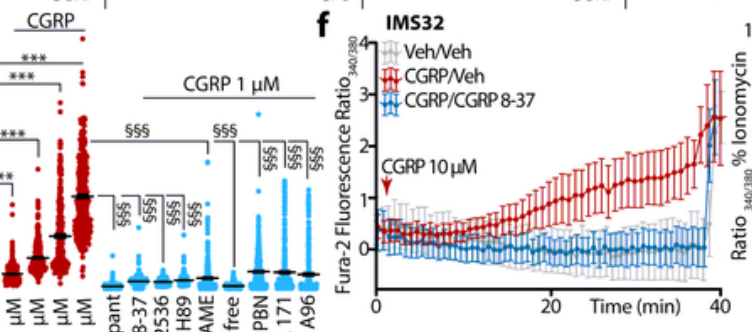

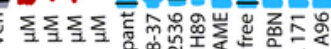
형영
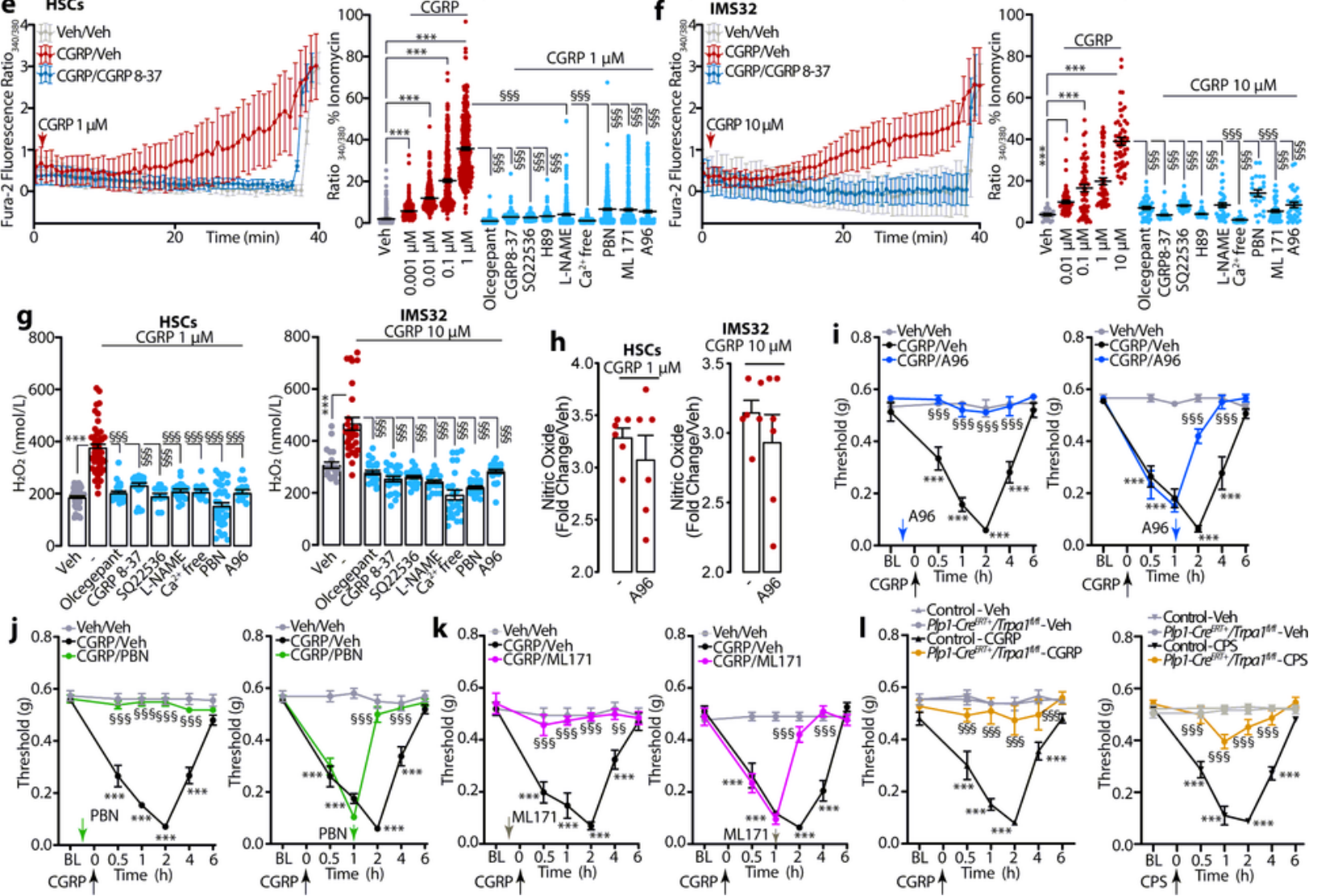


\section{Figure 7}

CGRP induces ROS release via Schwann cell TRPA1 activation. (a) Representative images of localization of immunoreactive DAPI, S100, RAMP1 and TRPA1 in human abdominal and mouse periorbital cutaneous nerve bundles (Scale: $10 \mu \mathrm{m}$ human, $50 \mu \mathrm{m}$ mouse, inset $10 \mu \mathrm{m})(\mathrm{n}=3$ subjects). (b) Pharmacological targets. (c, d) PMA after periorbital injection of CGRP (1.5 nmol), capsaicin (CPS, 50 pmol) or vehicles in (c) Trpa1+/+ and Trpa1/- mice and in (d) Adv-Cre+/Trpa1fl/fl or Control mice ( $\mathrm{n}=8$ mice per group). (e, f) Ca2+ response in HSCs and IMS32 cells exposed to CGRP $(10 \mu \mathrm{M})$ in the presence

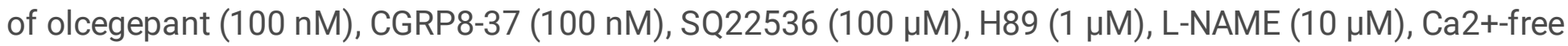
medium, PBN $(50 \mu \mathrm{M}), \mathrm{ML} 171(1 \mu \mathrm{M}), \mathrm{A} 967079$ (A96, $50 \mu \mathrm{M})$ or vehicle ( $\mathrm{n}=4$ independent experiments). (g) H2O2 release in HSCs and IMS32 cells exposed to CGRP $(10 \mu \mathrm{M})$ in the presence of olcegepant (100

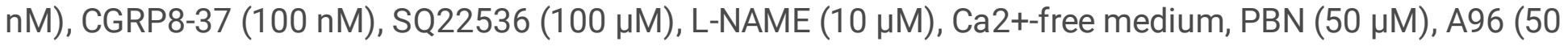
$\mu \mathrm{M})$, or vehicle ( $0.1 \% \mathrm{DMSO})$ ( $\mathrm{n}=3$ independent experiments). (h) Nitric oxide release in HSCs and IMS32 cells exposed to CGRP $(1$ or $10 \mu \mathrm{M})$ in the presence of $A 96(50 \mu \mathrm{M})$ or vehicle $(n=3$ independent experiments). (i-k) PMA after CGRP $(1.5 \mathrm{nmol})$ or vehicle in C57BL/6J mice pre-treated ( $0.5 \mathrm{~h}$, left) or posttreated (1h, right) with (i) A96 (300 nmol), (j) PBN (670 nmol) or (k) ML171 (250 nmol) or vehicle $(\mathrm{n}=8$ mice per group). (I) PMA after CGRP (1.5 nmol), CPS (50 pmol) or vehicles in Plp1-CreERT+/Trpa1fl/fl or Control mice treated with 4-OHT ( $n=8$ mice per group). Mean \pm SEM. (-) represents the combination of different vehicles. ${ }^{*} * \mathrm{P}<0.001$ vs. Trpa1+/+-Veh, Control-Veh, Veh and Veh/Veh; $\S \S P<0.01, \S \S \S P<0.001$ vs. Trpa1+/+-CGRP, Trpa1+/+-CPS, Control-CGRP, Control-CPS, CGRP $1 \mu \mathrm{M}$ and $1 \mu \mathrm{M}$, CGRP/Veh. 2-way (c, d, i-I) or 1-way (e-h) ANOVA, Bonferroni correction. 


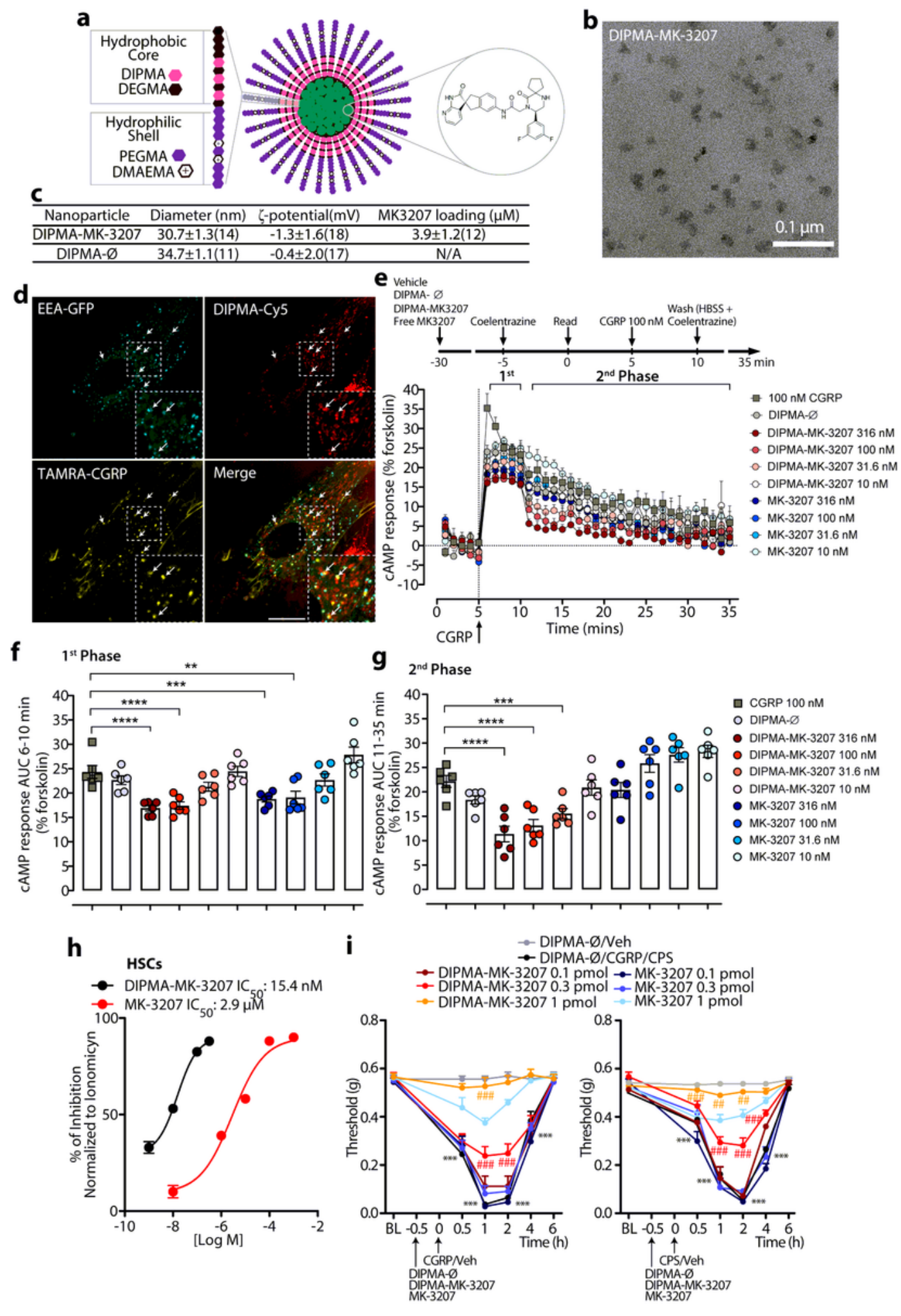

Figure 8

DIPMA-MK-3207 nanoparticles target endosomal CLR/RAMP1 signaling and provide superior relief from CGRP-evoked PMA. (a) pH-responsive DIPMA-MK-3207. (b) Transmission electron micrograph image of DIPMA-MK-3207 (Scale: $0.1 \mu \mathrm{m}$ ). (c) Physicochemical properties of DIPMA-MK-3207 and DIPMA- $\varnothing$. (d) Uptake of DIPMA-Cy5 into HSCs expressing EEA1-GFP. Cells were preincubated with DIPMA-Cy5 (40-60 $\mathrm{ng} / \mathrm{ml}$ ) for $30 \mathrm{~min}$ and were then incubated with TAMRA-CGRP (100 nM) for $30 \mathrm{~min}$. Arrows denote 
accumulation of TAMRA-CGRP in early endosomes containing DIPMA-Cy5. Representative images from $\mathrm{n}=5$ independent experiments (Scale: $10 \mu \mathrm{m}$ ). (e-g). Effects of DIPMA-MK-3207, MK-3207, DIPMA- $\varnothing$ or vehicle on CGRP- (100 nM) stimulated cAMP formation in HEK-rCLR/RAMP1 cells. (e) Time course and (f, g) integrated response (AUC, area under curve) before (1st phase) and after (2nd phase) washing to remove extracellular CGRP. (h) Concentration-response curves of the inhibition by DIPMA-MK-3207 or free MK-3207 on the Ca2+ response to CGRP in HSCs. Cells were preincubated with DIPMA-MK-3207 or MK$3207(1-1000 \mathrm{nM})$ for $20 \mathrm{~min}$ at room temperature to allow nanoparticle accumulation in endosomes.

Cells were washed, challenged with CGRP $(1 \mu \mathrm{M})$, and Ca2+ responses were measured for $40 \mathrm{~min}$.

Maximal responses are shown. $(\mathrm{i}, \mathrm{j}) \mathrm{PMA}$ in $\mathrm{C} 57 \mathrm{BL} / 6 \mathrm{~J}$ mice. Mice were pretreated by periorbital injection of DIPMA-MK-3207, MK-3207 (0.1, 0.3, 1 pmol), DIPMA- $\varnothing$ or vehicle. After 30 min, mice received periorbital injections of CGRP $(1.5 \mathrm{nmol})(\mathrm{I})$, capsaicin (CPS, $50 \mathrm{pmol})(\mathrm{j})$ or vehicle. $(\mathrm{n}=8$ mice per group). Mean $\pm S E M$. *** $P<0.001$ vs. DIPMA- $\varnothing /$ Veh, $\# \# P<0.01$, \#\#\#P<0.001 vs. MK-3207 0.3 pmol and MK-3207 1 pmol. (f) 2-way ANOVA, Bonferroni correction.

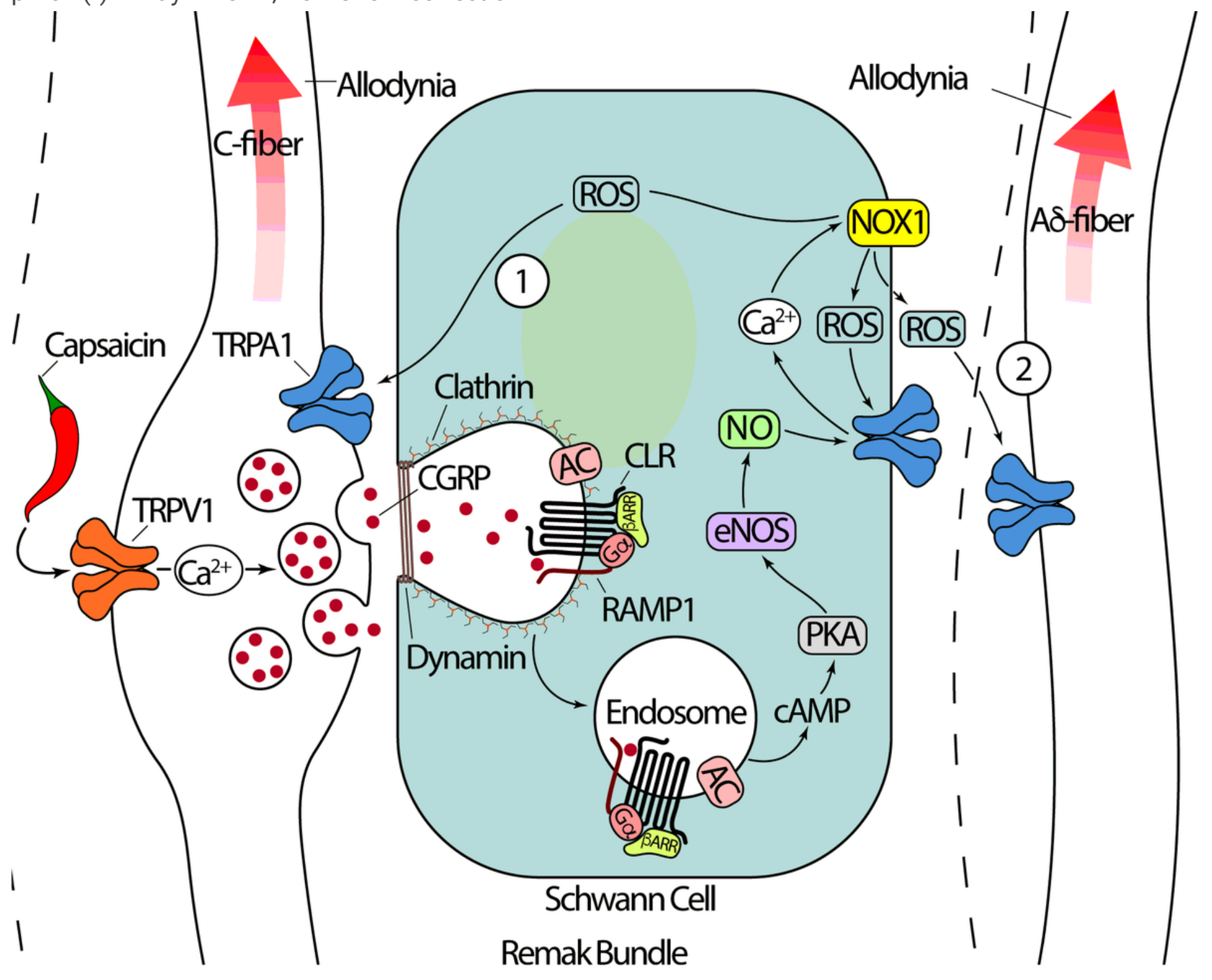

Figure 9 
Schematic representation of the pathway that signal prolonged cutaneous allodynia elicited by CGRP released and associated with neurogenic inflammation. The pro-migraine neuropeptide, CGRP, released from trigeminal cutaneous afferents, activates CLR/RAMP1 on Schwann cells. CLR/RAMP1 traffics to endosomes, where sustained G protein signaling increases CAMP and stimulates PKA that results in nitric oxide synthase activation. The ensuing release of nitric oxide targets the oxidant-sensitive channel, TRPA1, in Schwann cells, which elicits persistent ROS generation. ROS triggers TRPA1 on adjacent C- (1)

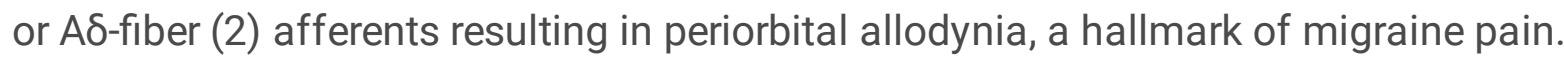

\section{Supplementary Files}

This is a list of supplementary files associated with this preprint. Click to download.

- DeLoguSuppIMaterial.pdf

- SuppVideo1.mp4

- SuppVideo2.mp4

- SuppVideo3.mp4

- SuppVideo4.mp4

- SuppVideo5.mp4

- SuppVideo6.mp4

- NCOMMS2128409nrreportingsummary3.pdf 